\title{
Numerical Investigation of Transient Phase Change in Horizontal Porous Channel with Localized Heating using Two-Equation Model
}

\author{
Mohammed A. Nima, PhD \\ Mechanical Engineering Department \\ College of Engineering- Baghdad University
}

\begin{abstract}
Transient phase change through a horizontal channel that subjected to discrete heat flux and filled with porous media of high-conductivity material, copper, is numerically investigated with $n$-pentane as the working fluid. The thermal non-equilibrium model is used in conjugate with the multiphase mixture model to analyze the transient behavior of fluid and solid phases. Three cases are studied regarding the position of the discrete heat flux: (1) discrete heat flux at the lower wall, (2) discrete heat flux at the upper wall and (3) discrete heat flux at both the lower and upper walls. Results show that the minimum liquid saturation and the maximum solid temperature (thermal non-equilibrium condition) are located above the heated suction. Results also show that the dryout zone is formed first at the upper wall due to the lower heat transfer from the upper heated wall. Temperature distribution for both solid and fluid phases, liquid saturation, vapor and liquid velocities are presented and analysed.
\end{abstract}

\section{Keywords}

Porous Media; Transient; Phase Change; Thermal nonequilibrium model; Horizontal Channel.

\section{INTRODUCTION}

Fluid flow and heat transfer with phase change in porous media is widely encountered in the engineering industry. Examples include thermally enhanced oil recovery, subsurface contamination and remediation, capillary-assisted thermal technologies, drying process, nuclear reactor safety analysis, high level radioactive waste repositories, and geothermal energy exploitation as reported by Wang and Cheng [1]. A new model was developed by Wang and Beckermann [2] to overcome the difficulties that arise when using the separate flow model SFM, which described by Bear [3], to solve the problem of two-phase flow in porous media. This new model is known as multiphase mixture model MMM. In the literature, the problem of heat transfer in porous media was solved based on thermal equilibrium TE and thermal non-equilibrium modelling TNE. In the TE model the fluid and the solid are in thermal equilibrium with each other and as a consequence have the same temperature at each point in the computational domain. In the TNE model the fluid and the solid are in thermal non-equilibrium and as a consequence have a different temperature at each point in the computational domain. In the TE model one energy equation must be solved to describe the heat transfer behavior in the porous structure, while in the TNE model two energy equations are required, one for the fluid phase and the other for the solid phase to predict the thermal behavior of each phase. In the present study, it will be assumed that there is a thermal non-equilibrium condition between the fluid phase and the solid phase. Thermal non-equilibrium approach has received less attention although it produces more realistic and reasonable results for the two-phase thermofluid flow analysis, Yuki et al. [4]. The heat dissipation in a high conductivity porous channel het sink was studied numerically by Peterson and Chang [5] under TNE condition. Their results show a remarkable enhancement in the mean heat transfer coefficient when a high conductivity material is added. Peterson and Chang [6] conducted an experimental simulation to verify their numerical solution [5]. Their results show that for low pressure drop, there was a good agreement between the numerical solution and the experimental work. The NTE approach was also used by Baytas and Pop [7] to study the free convection effect in a square cavity. Saeid [8] investigate numerically the mixed convection effect in a vertical porous layer by considering TNE approach for both aiding and opposing flow. The periodic free convection from a vertical heated plate was studied numerically by Saeid and Mohamad [9] with the adopted of the TNE model to investigate thermal conductivity ratio, thermal diffusivity ratio and heat transfer coefficient effects. Results show that the thermal conductivity ratio has the highest effect if compared with the thermal diffusivity ratio and heat transfer coefficient. Badruddin et al. [10] also used the TNE approach to investigate the effects of both natural convection and radiation heat transfer in a vertical annular of porous media. A modified two-phase mixture model of the original MMM was proposed by Yuki et al. [4]. They applied the new model for a porous media that subjected to high heat fluxes, and their results show a clear local thermal non-equilibrium in the two-phase region. The TNE model was also verified by Ahmed et al. [11] by solving the problem of mixed convection in a vertical annular of porous media. They found that TNE approach produces more realistic results.

In the present work, mixed convection of transient boiling heat transfer in a horizontal channel filled with metallic porous media and discretely heated, as shown in Fig. 1, will be numerically solved based on MMM with the use of TNE approach. Three cases are analyzed numerically: (1) discrete heat flux imposed at the lower wall, (2) discrete heat flux imposed at the upper wall and (3) discrete heat flux imposed at both the lower and upper walls. Temperature distribution for both solid and fluid phases, liquid saturation, vapor and liquid velocities are presented and analyzed.

To the best of the author knowledge, the study of transient mixed convection heat transfer with phase change in a horizontal channel that subjected to discrete heat flux with the use of thermal non-equilibrium model has not been reported previously in the literature. 


\section{MATHEMATICAL FORMULATION 2.1 Problem description}

The geometric configuration and the coordinate system are illustrated in Fig. 1. A two-dimensional horizontal channel of dimensions $(\mathrm{L} \times \mathrm{W})$ is filled with a metallic porous media (npentane/copper beads). At the inlet, sub-cooled n-pentane flows with a uniform inlet velocity of uin and inlet temperature of Tin. As shown in Fig. 1, a discrete heat flux is imposed at the lower wall (bottom heated $\mathrm{BH}$ ), upper wall (top heated $\mathrm{TH}$ ) and both the lower and upper walls (bottom and top heated BTH). As the sub-cooled n-pentane moves through the channel, its temperature increased at the walls adjacent to the heated sections. Boiling occurs when the heat flux increased sufficiently and a two-phase zone is formed adjacent to the heated sections and extends downstream induced by the gravity and buoyancy effects. At the exit, the n-pentane assumed to be thermally and hydraulically fully developed.

(a)
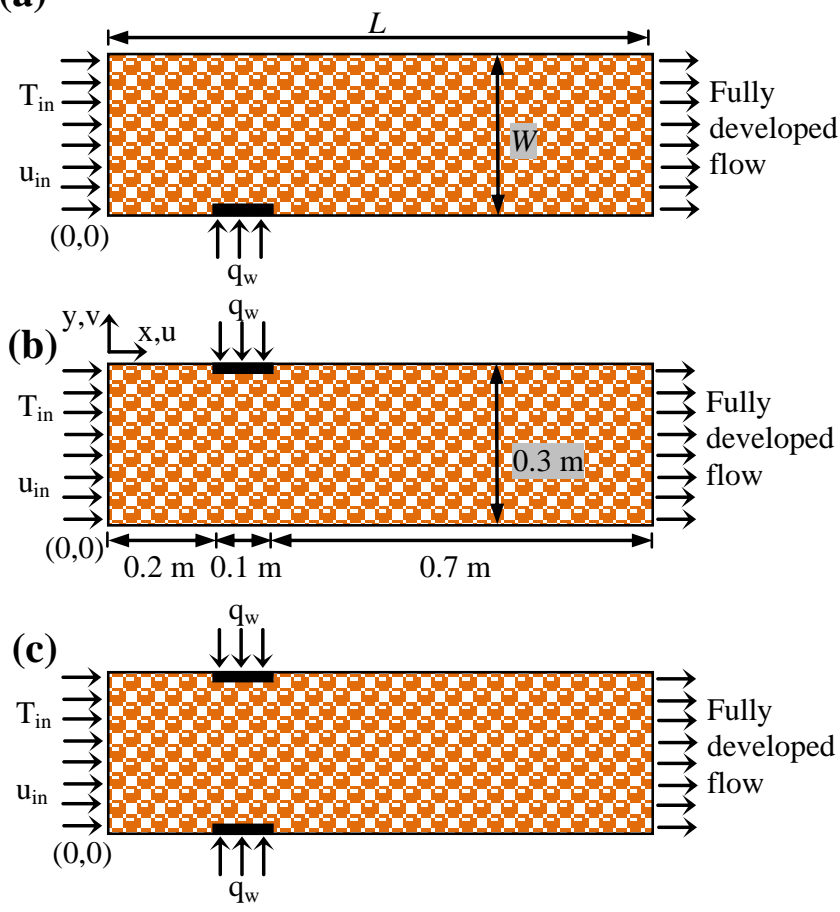

Fig. 1. Schematic of the physical problem: (a) bottom heated, (b) top heated, (c) bottom and top heated.

\subsection{Assumptions}

The major assumptions that govern this study are as follows:

1) The porous medium is rigid, uniform, isotropic and fully saturated with fluid.

2) Local thermal non-equilibrium approach will be applied between fluid phase and solid phase.

3) Forchheimer-extended Darcy flow model with Ergun expression for Forchheimer coefficient is applied to compute the mixture velocity and both liquid phase and vapor phase velocities.

4) In the two-phase region, the fluid is assumed to be isothermal at the saturation temperature.

5) The thermo-physical properties of both solid and fluid are assumed to be constant.

6) The thermal diffusion and dispersion that caused by the nature of the porous medium, are neglected.

\subsection{Governing equations}

The flow is modeled by the Forchheimer-extended Darcy flow model that accounts for the inertia effect in the porous structures:

$$
\nabla p=\underbrace{-\frac{K}{\mu} \mathbf{u}-\beta \rho|\mathbf{u}| \mathbf{u}}_{\text {Darcy Forchheimer }}
$$

where $\beta$ is the Forchheimer coefficient. Ergun [12] proposed an expression for the Forchheimer coefficient $\beta$, as:

$\beta=\frac{C_{E}}{\sqrt{K}}$

where $C_{E}$ is the Ergun constant and $K$ is the absolute permeability. From Eqs. (2) and (1), the Ergun equation can be written as:

$\nabla p=-\frac{K}{\mu} \mathbf{u}-\frac{C_{E}}{\sqrt{K}} \rho|\mathbf{u}| \mathbf{u}$

where:

$K=\frac{\varepsilon^{3} d_{p}^{2}}{150(1-\varepsilon)^{2}}$

$C_{E}=\frac{\sqrt{K}}{M} \quad M=\frac{\varepsilon^{3} d_{p}}{1.75(1-\varepsilon)}$

By adopting the multiphase mixture model MMM of Wang and Beckermann [2], the governing equations for the fluid phase can be written as:

1) Conservation of mass:

$\varepsilon \frac{\partial \rho}{\partial t}+\nabla \cdot(\rho \mathbf{u})=0$

2) Conservation of momentum:

$\rho \mathbf{u}=-\frac{K}{v+C_{E} \sqrt{K}|\mathbf{u}|}\left[\nabla p-\rho_{k} \mathbf{g}\right]$

3) Conservation of energy for fluid phase

$\Omega \frac{\partial H}{\partial t}+\nabla \cdot\left(\gamma_{h} \mathbf{u} H\right)=\nabla \cdot\left(\Gamma_{h} \nabla H\right)+\nabla \cdot\left[f_{s} \frac{K \Delta \rho h_{f g}}{v_{v}} \mathbf{g}\right]+Q_{s f}$

where

$\mathbf{g}=-\mathrm{g} \hat{y}$

The mixture variables and properties in Eqs. (6) to (8) are listed in Table 1.

Table 1. Variables in the multiphase mixture model.

\begin{tabular}{|l|c|}
\hline \multicolumn{1}{|c|}{ Variables } & Expressions \\
\hline Density & $\rho=\rho_{l} s+\rho_{v}(1-s)$ \\
\hline Velocity & $\rho \mathrm{u}=\rho_{l} \mathrm{u}_{l}+\rho_{v} \mathrm{u}_{v}$ \\
\hline Mixture enthalpy & $\rho h=\rho_{l} s h_{l}+\rho_{v}(1-s) h_{v}$ \\
\hline volumetric enthalpy & $H=\rho\left(h-2 h_{v s a t}\right)$ \\
\hline Kinetic density & $\rho_{k}=\rho_{l} \lambda_{l}(s)+\rho_{v} \lambda_{v}(s)$ \\
\hline Viscosity & $\mu=\frac{\rho_{l} s+\rho_{v}(1-s)}{k_{r l} / v_{l}+k_{r v} / v_{v}}$ \\
\hline $\begin{array}{l}\text { Advection correction } \\
\text { coefficient }\end{array}$ & $\frac{\gamma_{h}=}{\left.\left(2 \rho_{v} / \rho_{l}\right)(1-s)+s\right]\left[h_{v s a t}\left(1+\lambda_{l}\right)-h_{l s a t} \lambda_{l}\right]}$ \\
\hline
\end{tabular}




\begin{tabular}{|c|c|}
\hline $\begin{array}{l}\text { Effective heat } \\
\text { capacitance ratio }\end{array}$ & $\Omega=\varepsilon+\rho_{S} c_{S}(1-\varepsilon) \frac{d T}{d H}$ \\
\hline $\begin{array}{l}\text { Effective thermal } \\
\text { diffusion coefficient }\end{array}$ & $\begin{array}{c}\Gamma_{h}=\frac{1}{1+\left(1-\rho_{v} / \rho_{l}\right) h_{v s a t} / h_{f g}} D \\
+k_{f, \text { eff }} \frac{d T}{d H}\end{array}$ \\
\hline $\begin{array}{l}\text { Capillary diffusion } \\
\text { coefficient }\end{array}$ & $D(s)=\frac{\sqrt{\varepsilon K} \sigma}{\mu_{l}} \frac{k_{r l} k_{r v}}{\left(v_{v} / v_{l}\right) k_{r l}+k_{r v}}\left[-J^{\prime}(s)\right]$ \\
\hline Relative mobility & $\begin{array}{l}\lambda_{l}(s)=\frac{k_{r l} / v_{l}}{k_{r l} / v_{l}+k_{r v} / v_{v}} \\
\lambda_{v}(s)=\frac{k_{r v} / v_{v}}{k_{r l} / v_{l}+k_{r v} / v_{v}}\end{array}$ \\
\hline Hindrance function & $f(s)=\frac{k_{r l} k_{r v} / v_{l}}{k_{r l} / v_{l}+k_{r v} / v_{v}}$ \\
\hline $\begin{array}{l}\text { Relative } \\
\text { permeabilities }\end{array}$ & $k_{r l}=s^{3}, k_{r v}=(1-s)^{3}$ \\
\hline Capillary pressure & $\begin{aligned} p_{c}(s)=\sqrt{\frac{\varepsilon}{K}} \sigma J(s) \\
J(s)=1.417(1-s) \\
-2.12(1-s)^{2} \\
+1.263(1-s)^{3}\end{aligned}$ \\
\hline
\end{tabular}

The temperature and the liquid saturation can be calculated from the enthalpy as:

$$
\begin{aligned}
& T= \\
& \begin{cases}\frac{H+2 \rho_{l} h_{v s a t}}{\rho_{l} c_{l}} & H \leq-\rho_{l}\left(2 h_{v s a t}-h_{\text {lsat }}\right) \\
T_{\text {sat }} & -\rho_{l}\left(2 h_{v s a t}-h_{\text {lsat }}\right)<H \leq-\rho_{v} h_{v s a t} \\
T_{\text {sat }}+\frac{H+\rho_{v} h_{v s a t}}{\rho_{v} c_{v}} & -\rho_{v} h_{v s a t}<H\end{cases}
\end{aligned}
$$

$$
\begin{aligned}
& s= \\
& \begin{cases}1 & H \leq-\rho_{l}\left(2 h_{v s a t}-h_{l s a t}\right) \\
-\frac{H+\rho_{v} h_{v s a t}}{\rho_{l} h_{f g}+\left(\rho_{l}-\rho_{l}\right) h_{v s a t}} & -\rho_{l}\left(2 h_{v s a t}-h_{l s a t}\right)<H \leq-\rho_{v} h_{v s a t} \\
0 & -\rho_{v} h_{v s a t}<H\end{cases}
\end{aligned}
$$

Subscripts 1 and $v$ refer to the liquid and vapor respectively. The liquid and vapor velocity can be calculated based on Forchheimer-extended Darcy flow model, Eq. (7), as follows:

$$
\begin{aligned}
& \rho_{l} \mathbf{u}_{l}=-\frac{K k_{r l}}{v_{l}+C_{E} \sqrt{K k_{r l}}\left|\mathbf{u}_{l}\right|}\left[\nabla p_{l}-\rho_{l} \mathbf{g}\right] \\
& \rho_{v} \mathbf{u}_{v}=-\frac{K k_{r v}}{v_{v}+C_{E} \sqrt{K k_{r v}}\left|\mathbf{u}_{v}\right|}\left[\nabla p_{v}-\rho_{v} \mathbf{g}\right]
\end{aligned}
$$

where $\nabla p_{l}$ and $\nabla p_{v}$ are defined according to Wang and Beckermann [2] as:

$$
\begin{aligned}
& \nabla p_{v}=\nabla p+\lambda_{l}(s) \nabla p_{c}(s) \\
& \nabla p_{l}=\nabla p+\lambda_{v}(s) \nabla p_{c}(s)
\end{aligned}
$$

The thermal non-equilibrium model TNE will be completed by adding an energy equation for the solid phase as:

$\nabla .\left(k_{s, \mathrm{eff}} \nabla T_{s}\right)-Q_{s f}=0$

The effective thermal conductivities for both fluid and solid phases are defined as follows: $k_{s, \mathrm{eff}}=(1-\varepsilon) k_{S}$

$k_{f, \text { eff }}=\varepsilon\left[k_{l} s+k_{v}(1-s)\right]$

In the thermal non-equilibrium model, the local temperature of the fluid phase at each point is assumed to be different from that of the solid phase at the same point, and as a result a finite amount of heat transfer $\left(Q_{s f}\right)$ will take place between the fluid and the solid phases. In the single phase region $(s=1)$, the volumetric heat transfer $\left(Q_{s f}\right)$ can be expressed as:

$Q_{s f}=h_{s f} a\left(T_{s}-T_{f}\right)$

where;

$a$, represents the solid-fluid contacting area per unit volume and according to Dullien [13] it can be expressed as:

$a=\frac{6(1-\varepsilon)}{d_{p}}$

$h_{s f}$, represents the fluid-to-solid heat transfer coefficient correlated by Wakao and Kaguei [14]:

$h_{s f}=\frac{k_{l}}{d_{p}}\left(2+1.1 \operatorname{Pr}_{l}^{1 / 3} \operatorname{Re}_{p, l}^{0.6}\right)$

where $\operatorname{Re}_{p, l}=|\mathrm{u}| d_{p} / \mu_{l}$. In the two-phase region $(0<s<1)$, the boiling heat transfer will be calculated based on the pool boiling correlation that developed by Rohsenow [15]:

$q_{\text {boil }}=\mu_{l} h_{f g}\left(\frac{\mathrm{g}\left(\rho_{l}-\rho_{v}\right)}{\sigma}\right)^{1 / 2}\left(\frac{c_{l}\left(T_{s}-T_{s a t}\right)}{C_{s f} h_{f g}}\right)^{3} \operatorname{Pr}_{l}^{1.7 / 0.33}$

where $C_{s f}$ is a constant and its value depends on the combination between the heating metal surface and the working fluid. In the present study a value of $C_{s f}=0.0154$ (n-pentane/copper) is used.

Finally, the volumetric heat transfer $\left(Q_{s f}\right)$ in the two-phase region can be modelled by weighting the boiling heat transfer in Eq. (22) by the liquid saturation:

$Q_{s f}=a s q_{\text {boil }}$

Other thermophysical properties of the $n$-pentane/copper beads (Beaton and Hewitt [16]) are listed in Table 2.

Table 2. Thermophysical properties of the $n$-pentane/copper beads system.

\begin{tabular}{|c|c|c|c|c|}
\hline Property & Symbol & Solid & Liquid & Vapor \\
\hline $\begin{array}{c}\text { Saturation } \\
\text { temperature }\end{array}$ & $\begin{array}{c}T_{\text {sat }} \\
{ }^{\circ} \mathrm{C}\end{array}$ & --- & \multicolumn{2}{|c|}{36.06} \\
\hline Density & $\begin{array}{c}\rho \\
\mathrm{kg} / \mathrm{m}^{3}\end{array}$ & 8954 & 610.2 & 3.007 \\
\hline $\begin{array}{c}\text { Thermal } \\
\text { conductivity }\end{array}$ & $k$ & 386 & 0.107 & 0.0167 \\
\hline $\begin{array}{c}\text { Specific } \\
\text { heat }\end{array}$ & $\begin{array}{c}\mathrm{c} \\
\mathrm{J} / \mathrm{kg} \mathrm{K}\end{array}$ & 383.1 & 2340 & 1790 \\
\hline $\begin{array}{c}\text { Dynamic } \\
\text { viscosity }\end{array}$ & $\begin{array}{c}\mu \\
\mathrm{kg} / \mathrm{m} . \mathrm{s}\end{array}$ & --- & $\begin{array}{c}1.96 \\
\times 10^{-4}\end{array}$ & $\begin{array}{l}6.9 \\
\times 10^{-6}\end{array}$ \\
\hline $\begin{array}{c}\text { Interfacial } \\
\text { tension }\end{array}$ & $\begin{array}{c}\sigma \\
\mathrm{N} / \mathrm{m}\end{array}$ & --- & \multicolumn{2}{|c|}{0.0143} \\
\hline
\end{tabular}




\begin{tabular}{|c|c|c|c|c|}
\hline $\begin{array}{c}\text { Latent heat } \\
\text { of } \\
\text { evaporation }\end{array}$ & $\begin{array}{c}h_{f g} \\
\mathrm{~J} / \mathrm{kg}\end{array}$ & --- & \multicolumn{2}{|c|}{358200} \\
\hline $\begin{array}{c}\text { Prandtl } \\
\text { number }\end{array}$ & $\operatorname{Pr}$ & --- & 4.29 & 0.74 \\
\hline
\end{tabular}

The physical parameters for the copper beads that used in the present study are listed in Table 3.

Table 3. Physical parameters for the copper beads.

\begin{tabular}{|c|c|}
\hline $\begin{array}{c}\text { Mean diameter } \\
d_{p}(\mathrm{~mm})\end{array}$ & 0.5 \\
\hline $\begin{array}{c}\text { Porosity } \\
\varepsilon\end{array}$ & 0.4 \\
\hline $\begin{array}{c}\text { Permeability } \dagger \\
K\left(\mathrm{~m}^{2}\right)\end{array}$ & $1.6913 \times 10^{-10}$ \\
\hline
\end{tabular}

$\dagger$ Calculated from Eq. (4).

\subsection{Initial and Boundary Conditions}

The initial and boundary conditions for the present problem are listed in Table 4.

Table 4. Initial and boundary conditions.

\begin{tabular}{|c|c|c|}
\hline $\begin{array}{l}\text { Initial } \\
\text { Conditions }\end{array}$ & At $t=0$ & $\begin{array}{c}\mathrm{u}=\mathrm{v}=0 \\
T_{s}=T_{i n} \\
H=\rho_{l}\left(c_{l} T_{\text {in }}-2 h_{\text {vsat }}\right)\end{array}$ \\
\hline \multirow{4}{*}{$\begin{array}{l}\text { Boundary } \\
\text { Conditions }\end{array}$} & $\begin{array}{l}\text { At the inlet } \\
(x=0)\end{array}$ & $\begin{array}{c}\mathrm{u}=\mathrm{u}_{\mathrm{in}}, \mathrm{v}=0 \\
(1-\varepsilon) k_{s} \frac{\partial T_{s}}{\partial x}=0 \\
H=\rho_{l}\left(c_{l} T_{\text {in }}-2 h_{\text {vsat }}\right)\end{array}$ \\
\hline & $\begin{array}{l}\text { At the outlet } \\
(x=L)\end{array}$ & $\begin{array}{c}(1-\varepsilon) k_{s} \frac{\partial T_{s}}{\partial x}=0 \\
\frac{\partial H}{\partial x}=0\end{array}$ \\
\hline & $\begin{array}{l}\text { Adiabatic } \\
\text { walls }\end{array}$ & $\begin{array}{c}\mathrm{v}=0 \quad \text { (impermeable) } \\
(1-\varepsilon) k_{s} \frac{\partial T_{s}}{\partial y}=0 \\
-\Gamma_{h} \frac{\partial H}{\partial y}+f_{s} \frac{K \Delta \rho h_{f g}}{v_{v}} \mathrm{~g}=0\end{array}$ \\
\hline & $\begin{array}{l}\text { Heated } \\
\text { sections }\end{array}$ & $\begin{array}{c}\mathrm{v}=0 \quad \text { (impermeable) } \\
(1-\varepsilon) k_{s} \frac{\partial T_{s}}{\partial y}=q_{s} \\
-\Gamma_{h} \frac{\partial H}{\partial y}+f_{s} \frac{K \Delta h_{f g}}{v_{v}} \mathrm{~g}=q_{f} \\
q_{s}+q_{f}=q_{w}\end{array}$ \\
\hline
\end{tabular}

We assumed that the solid phase and the fluid phase are in thermal non-equilibrium, then each phase (solid and fluid) must absorb a different amount of energy $\left(q_{s}\right.$ and $\left.q_{f}\right)$ from the total supplied energy $\left(q_{w}\right)$ at the heated sections. The relation $\left(q_{s}+q_{f}=q_{w}\right)$ is not enough by itself to divide the total supplied energy $\left(q_{w}\right)$ into $q_{s}$ and $q_{f}$. An additional relation that developed by Oda et al. [17] is also used to calculate $q_{s}$ and $q_{f}$ by performing a conjugate between heat transfer in the porous media and heat conduction in a solid wall:

$\frac{q_{f}}{q_{s}}=\frac{k_{f, \text { eff }}}{k_{s, \text { eff }}} \frac{T_{w f}-T_{f}}{T_{w s}-T_{s}}$

where;

$T_{f}$ and $T_{s}$, represent the the temperatures of fluid and solid phases in the vicinity of the heated wall.

$T_{w f}$ and $T_{w s}$, represent the the temperatures of fluid and solid phases at the heated wall.

\subsection{Numerical Procedure}

In the present study, the momentum equation [Eq. (7)], is discretized by the finite volume method and solved with the associated boundary conditions by SIMPLE algorithm of Patankar [18] by using line-by-line tri-diagonal matrix algorithm TDMA. When the pressure field is computed, the velocity field can be obtained from the momentum equation, Eq. (7). The individual velocities of liquid and vapor are then calculated using Eqs. (12) and (13), and they stored at the interfaces of the control volumes.

The pressure at the exit section, $P_{i, j \max }^{k+1}$, was calculated depending on the conservation of mass between the inlet and outlet sections:

$\frac{P_{i, j \max }^{k+1}-P_{i, j \max -1}^{k}}{\Delta y}=-G^{\prime \prime}\left[\frac{\rho \mathrm{v}\left(v+C_{E} \sqrt{K}|\mathrm{u}|\right)}{K}+\rho_{k} \mathrm{~g} \cos \phi\right]_{i, j \max }^{k}$

where $G^{\prime \prime}$, is the mass flow rate ratio:

$G^{\prime \prime}=\frac{\dot{m}}{\int(\rho \mathrm{v})_{i, j \max } d x}$

When the overall mass conservation is achieved, $G^{\prime \prime}$ will approach unity and the pressure field will be obtained for the entire domain.

After obtaining the pressure field, the fluid energy equation, Eq. (8), was solved by a fully implicit control volume formulation with the use of the power law scheme of Patankar [18] to discretize the combined convective and conductive terms. The temperature and the liquid saturation could be calculated from the enthalpy, based on Eqs. (10) and (11). Finally the solid energy equation, Eq. (16), is discretized by the finite volume method and the resulting equation was solved by using line-by-line tri-diagonal matrix algorithm TDMA to obtain the temperature of the solid phase.

A relative error of less than $10^{-5}$ is required for both the velocity and temperature fields between successive iterations, and the normalized residual for the pressure and enthalpy field are less than $10^{-7}$ to achieve convergence.

$\bar{R}=\frac{\sum\left|a_{e} \phi_{e}+a_{w} \phi_{w}+a_{n} \phi_{n}+a_{s} \phi_{s}+b-a_{p} \phi_{p}\right|}{\sum\left|a_{p} \phi_{p}\right|} \leq 10^{-7}$

\subsection{Code Validation}

To validate the present code, a comparison was made with Peterson and Chang [5] results, which obtained for a horizontal porous channel of $2.5,5$ and $10 \mathrm{~mm}$ height and 25 $\mathrm{mm}$ length with different inlet velocity for each channel height and constant inlet temperature of Tin $=95^{\circ} \mathrm{C}$ for all cases. The channel was filled with sintered copper beads with mean diameter of $0.1 \mathrm{~mm}$ and subjected to constant heat fluxes of 80,40 and $20 \mathrm{~W} / \mathrm{cm} 2$ from one side and the other side is adiabatic. Figure 2 shows a good matching with Peterson and Chang [5] results.

\section{RESULTS AND DISCUSSION}

In the present study, the problem of transient boiling heat transfer through a horizontal channel that subjected to discrete heat flux is solved based on the thermal non-equilibrium model. Numerical computations were performed for a horizontal channel of $0.3 \mathrm{~m}$ height and $1 \mathrm{~m}$ length. The channel is packed with copper beads of $0.5 \mathrm{~mm}$ diameter that saturated with n-pentane as the working fluid. The discrete 
heat flux is supplied at a distance of $0.2 \mathrm{~m}$ from the channel inlet and the heated section length is $0.1 \mathrm{~m}$. The fluid enters the channel with a constant temperature and velocity of Tin $=20^{\circ} \mathrm{C}$ and uin $=1 \mathrm{~mm} / \mathrm{s}$, respectively. The imposed heat flux in both cases of $\mathrm{BH}$ and $\mathrm{TH}$ is $120 \mathrm{~kW} / \mathrm{m} 2$. In the case of $\mathrm{BTH}, 100 \mathrm{~kW} / \mathrm{m} 2$ is supplied at the bottom and the top heated

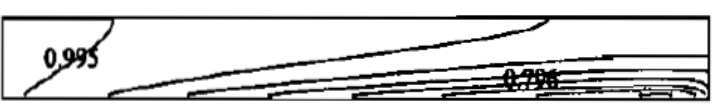

Peterson and Chang [5]

(a)

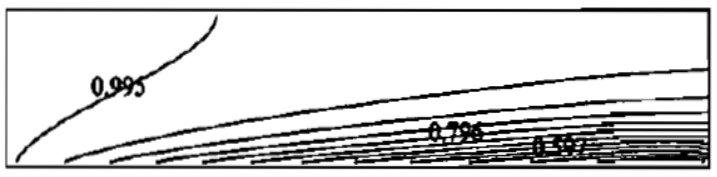

Peterson and Chang [5]

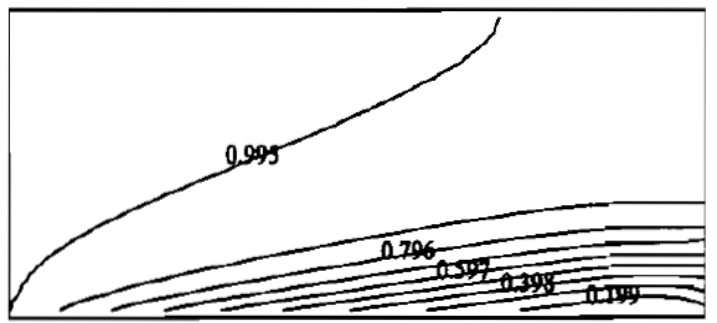

Peterson and Chang [5]

(b)

section with a total imposed heat flux of $200 \mathrm{~kW} / \mathrm{m} 2$. A grid independent study is carried out and the results showed that the mesh of $70 \times 180$ with $\Delta \mathrm{t}=0.5 \mathrm{~s}$ produces a gridindependent solution. For all cases, the results are presented at $\mathrm{t}=10 \mathrm{~s}, 150 \mathrm{~s}, 1000 \mathrm{~s}, 4000 \mathrm{~s}, 8000 \mathrm{~s}$ and at steady state condition $(10000 \mathrm{~s})$.

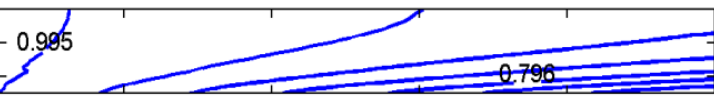

Present study

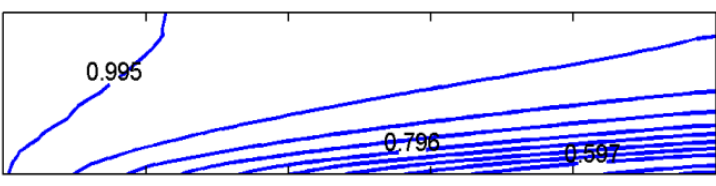

Present study

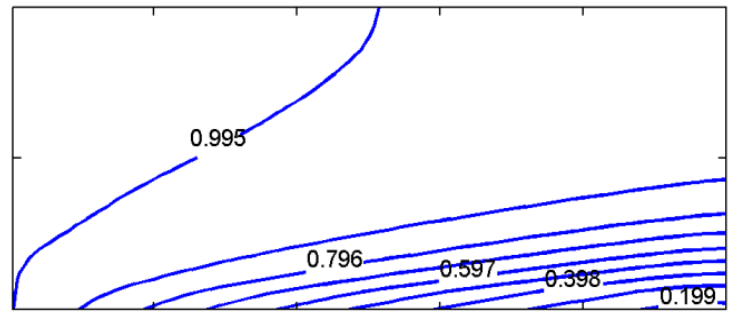

Present study

(c)

Fig. 2. Liquid saturation distribution for different channel heights with constant mass flow rate: $d_{p}=0.1 \mathrm{~mm}, L_{\mathrm{x}}=25 \mathrm{~mm}$, q $=80 \mathrm{~W} / \mathrm{cm}^{2}$, (a) $L_{\mathrm{y}}=2.5 \mathrm{~mm}, \mathrm{v}_{\mathrm{in}}=2 \mathrm{~cm} / \mathrm{s}$; (b) $L_{\mathrm{y}}=5 \mathrm{~mm}, \mathrm{v}_{\mathrm{in}}=1 \mathrm{~cm} / \mathrm{s}$; (c) $L_{\mathrm{y}}=10 \mathrm{~mm}, \mathrm{v}_{\mathrm{in}}=0.5 \mathrm{~cm} / \mathrm{s}$.

\subsection{Lower wall discrete heat flux effects bottom heated case (BH)}

Figs. 3-5 show the influence of the lower wall discrete heat flux $(\mathrm{qw}=120 \mathrm{~kW} / \mathrm{m} 2)$ on the transient behavior of fluid and solid phases. A bold solid line is used to separate the subcooled liquid region from the two-phase region to combine the two regions in a single contour plot for more clarification. The bold solid line represents the condensation front that divided the contour plot to liquid saturation contours (twophase region that labeled with the corresponding values of the liquid saturation $s=0$ to 1) and fluid temperature contours (sub-cooled liquid region that labeled with the corresponding values of the fluid temperatures $T_{f}=20$ to $36.06{ }^{\circ} \mathrm{C}$ ). The bold solid line (condensation front) is also used to separate the vapor velocity vectors from the liquid velocity vectors as they presented in one figure.

After $10 \mathrm{~s}$ [Fig. 3a], the temperature of the fluid near the heated wall increased slightly due to the activation of the discrete heat flux at the lower wall. At this stage and due to the small portion of heat that transferred to the fluid-solid structure, the solid phase is in thermal equilibrium with fluid phase and this can be seen clearly from Figs. $3 a$ and $4 a$. The small temperature difference at the heated wall caused a small buoyancy effect and as a result the velocity vectors remains parallel to the heated wall except at the channel exit where the fluid deflect towards the lower wall due to the gravity effect as shown in Fig. 5a. At $\mathrm{t}=150 \mathrm{~s}$ and with the continuous heating, the onset of boiling occurs as a thin layer above the heated wall as shown in Fig. 3b. The buoyancy force increased but it still unable to change the flow structure and this can be seen from the uniform distribution of the isotherms above the heated section which have a profile that similar to a conduction heat transfer through the porous structure (dome shape). With the two-phase onset, the solid phase isotherms [Fig. 4b] indicate that the solid structure near the heated wall is no longer in thermal equilibrium with the fluid-phase. Only a small portion of the fluid becomes vapor at $t=150 \mathrm{~s}$ [Fig. $5 b]$, and this vapor caused a reduction in the amount of the heat transferred.

When more time elapsed, $[t=1000 \mathrm{~s}$ (Fig. $5 \mathrm{c}$ ) and $\mathrm{t}=4000 \mathrm{~s}$ (Fig. 5d)], the two-phase zone expands and more vapor is generated. It can be seen that the vapor flows upwards far from the heated section and this can be attributed to the buoyancy effect that derived by the density difference between the vapor at the heated section and the incoming subcooled liquid. The generated vapor reduced the permeability in the two-phase zone and as a consequences, the incoming fluid deflect around the condensation front. Fig. $3 \mathrm{c}$ and $3 \mathrm{~d}$ shows that the expansion of the two-phase zone is accompanied with a reduction in the liquid saturation with a minimum value of, $s=0.2$, is recorded above the heated suction. It can also be seen from Fig. $3 c$ and $3 d$ that with the spread of the two-phase zone, the temperature distribution is no longer have the uniform dome shape above the heated suction. As the buoyancy effect increased due to the density difference, the isotherms lost their uniform shape and deflect away from the heated suction towards the inlet and the outlet of the porous channel. The incoming sub-cooled liquid at the channel inlet (before the heated suction) caused a change in 
the isotherms inclination towards the channel exit as shown in Fig. 3d. The comparison of Fig. 4e with Fig. 3e reveals that the non-thermal equilibrium condition between the fluid phase and the solid phase becomes more obvious above the heated suction and it reduced gradually far from the heated suction affected by the incoming sub-cooled liquid.

At $\mathrm{t}=10000 \mathrm{~s}$, the steady state is reached and the two-phase zone expands to the channel exit with a minimum value of liquid saturation is recorded above the heated suction as
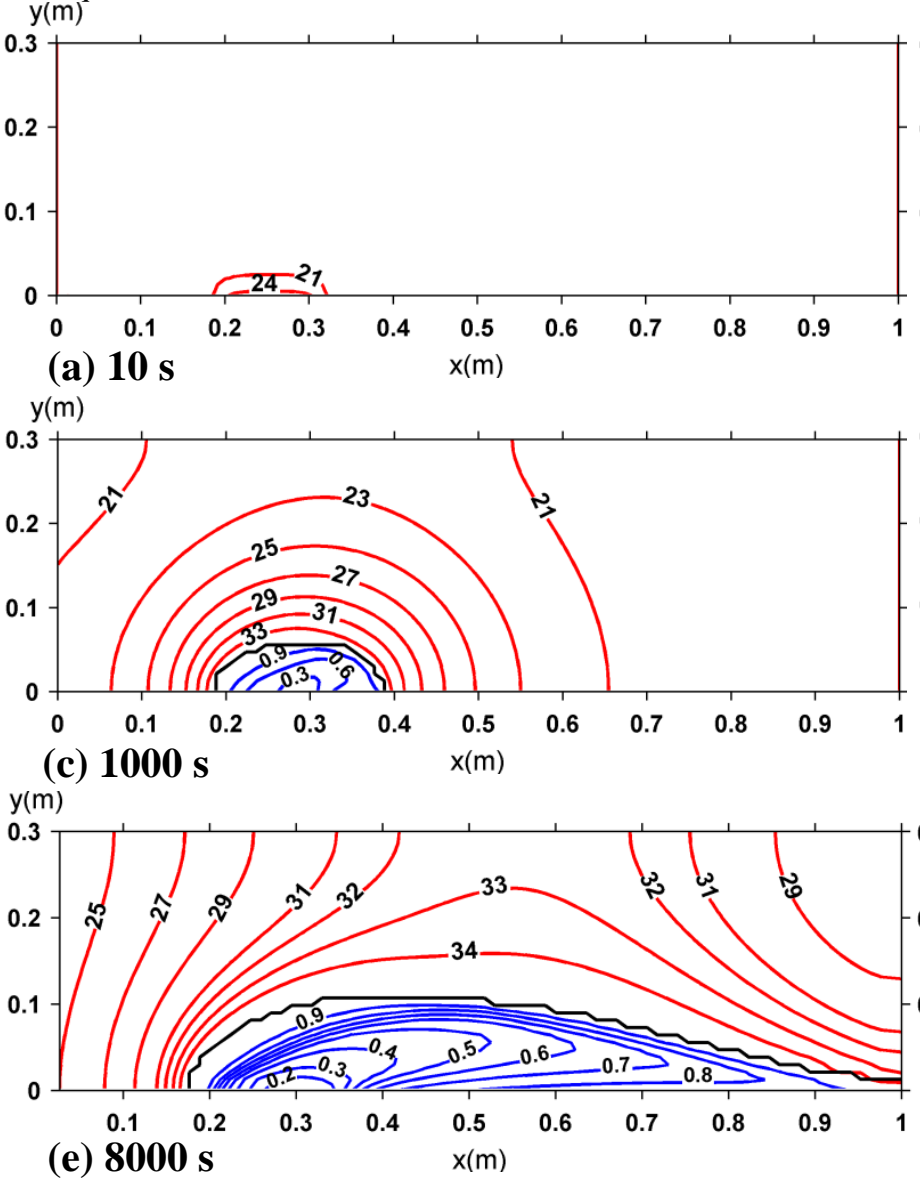

Fig. 3. Fluid temperature and liquid saturation contours (bottom heated BH).

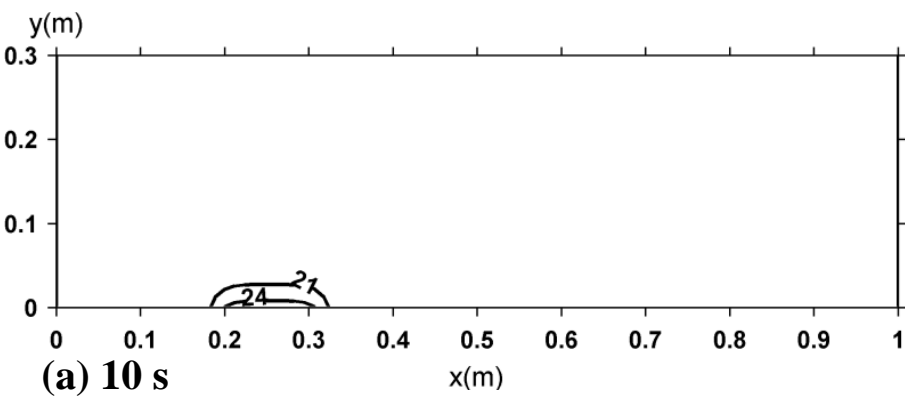

$\mathrm{y}(\mathrm{m})$

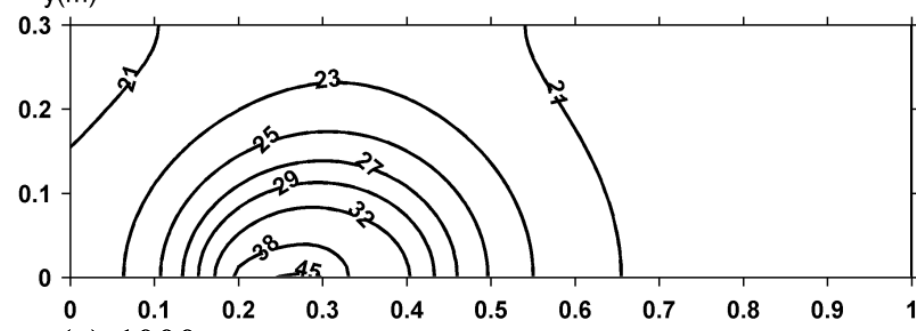

(c) $1000 \mathrm{~s}$ shown in Fig. 3f. The growth of the two-phase region is affected by the incoming sub-cooled liquid, the growth is moved upward from the leading edge of the heated section and then it turned down towards the channel exit. The effect of the incoming sub-cooled liquid in the two-phase region is greater at the channel exit from that at the heated suction; this can be seen clearly from Fig. $5 \mathrm{f}$ where the vapor velocity is vanished from the trailing edge of the heated suction towards the channel exit.

$y(m)$

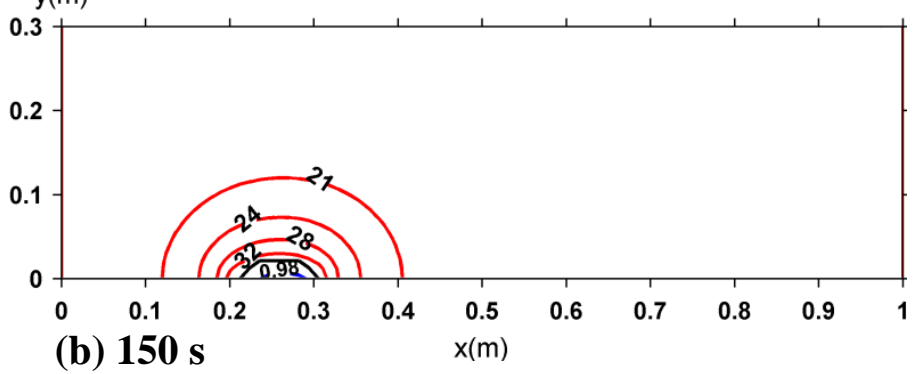

$y(m)$

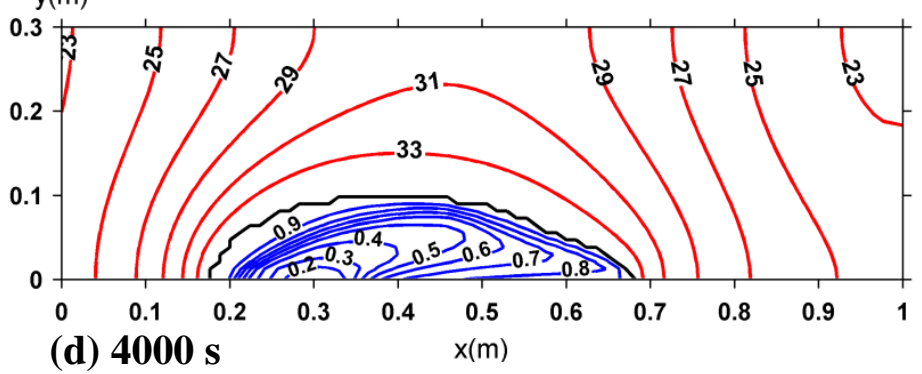

$y(m)$

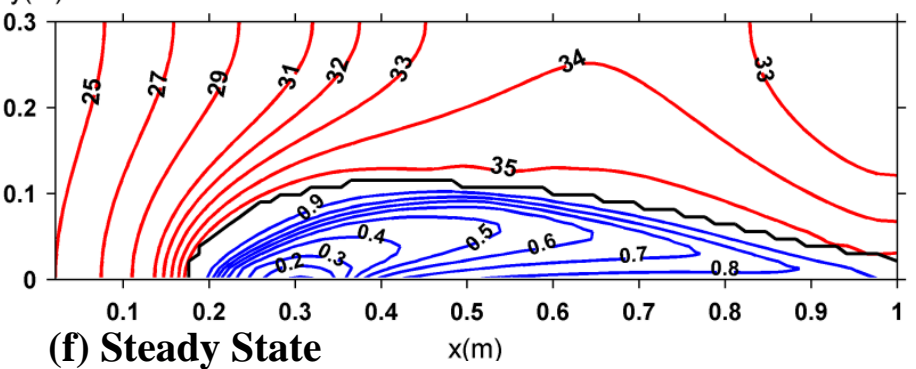

$y(m)$

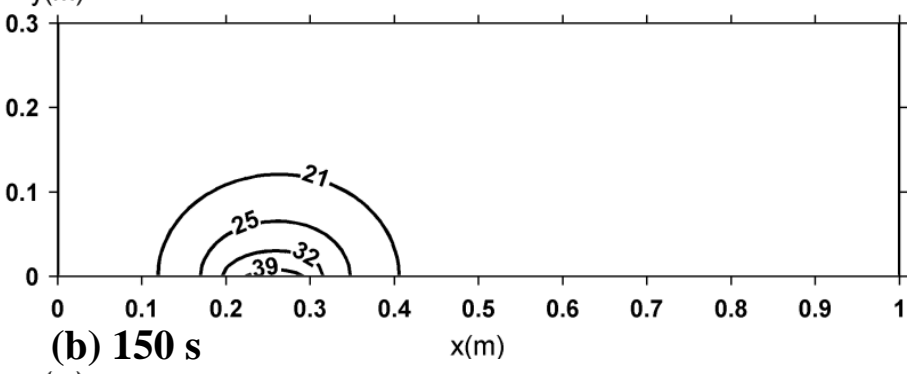
$\mathrm{y}(\mathrm{m})$

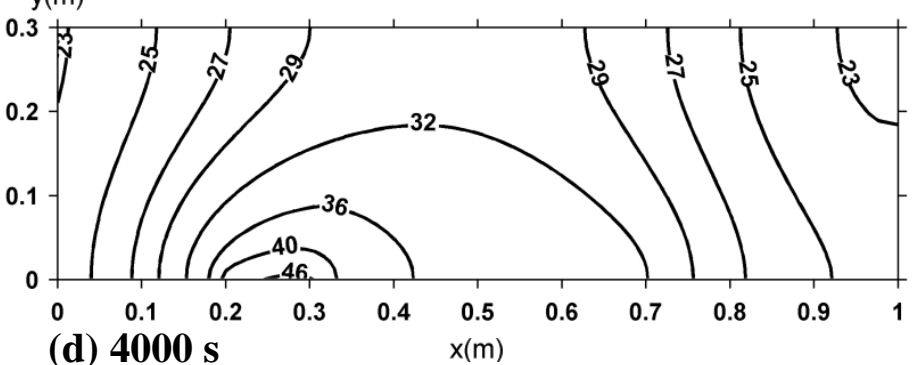



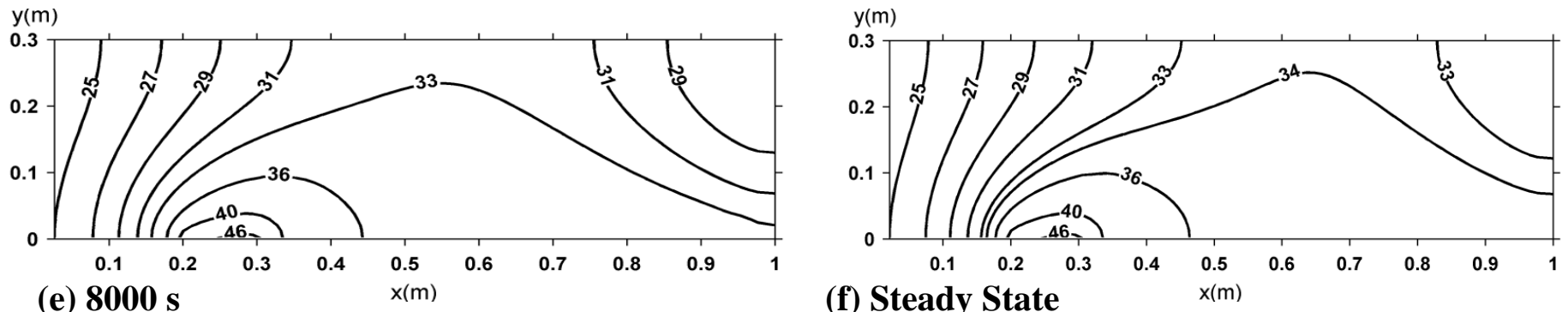

\section{$\mathrm{y}(\mathrm{m})$}

Fig. 4. Solid temperature contgyrs (bottom heated BH).

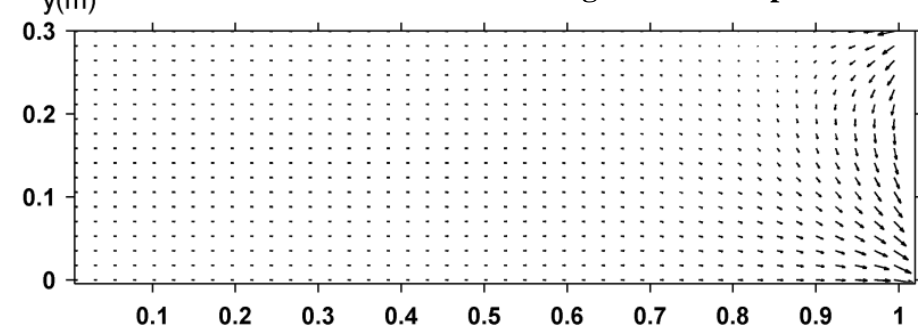

(a) $10 \mathrm{~s}$

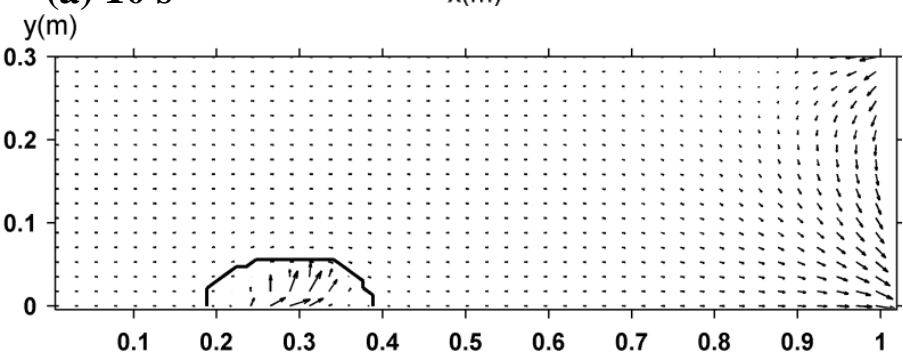

(c) $1000 \mathrm{~s}$

$\mathrm{x}(\mathrm{m})$

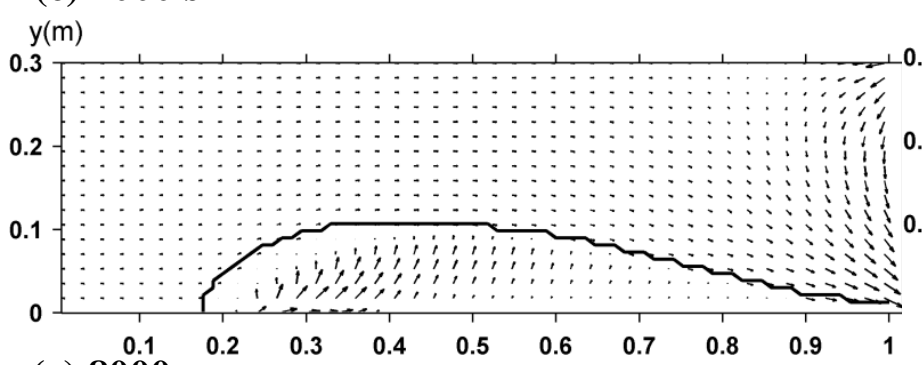

(e) $8000 \mathrm{~s}$ $\mathrm{x}(\mathrm{m})$

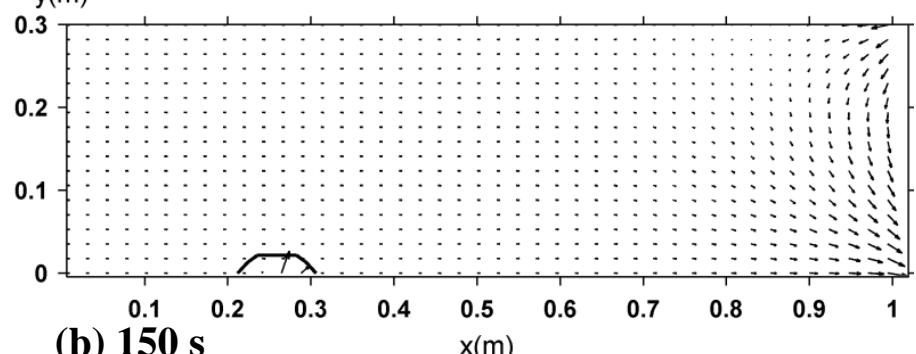

(b) $150 \mathrm{~s}$

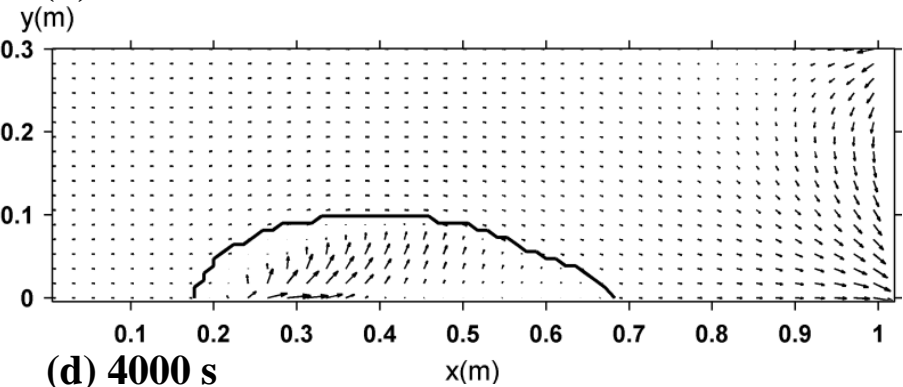

$y(\mathrm{~m})$

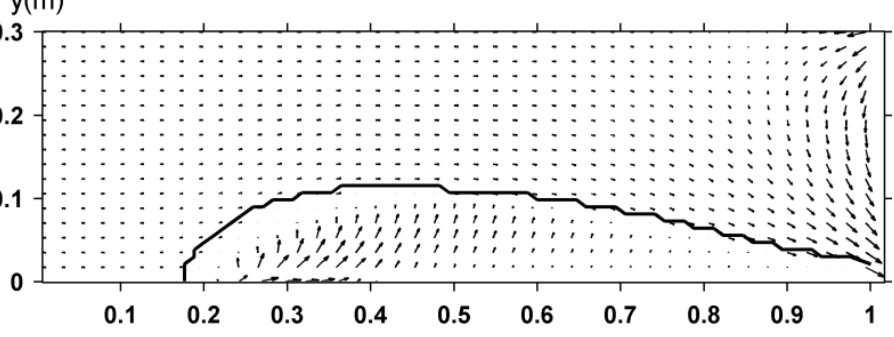

(f) Steady State $x(m)$

Fig. 5. Liquid and vapor velocity vectors (bottom heated $B H$ ).

\subsection{Upper wall discrete heat flux effects - top heated case $(\mathrm{TH})$}

Figs. 6-8 show the influence of the upper wall discrete heat flux $(\mathrm{qw}=120 \mathrm{~kW} / \mathrm{m} 2)$ on the transient behavior of fluid and solid phases. At the beginning and with the small buoyancy effect, the flow structure is similar in some aspects to the $\mathrm{BH}$ case. A reversed uniform dome shape for the isotherms can be seen at the beginning of heating $[\mathrm{t}=10 \mathrm{~s}$ (Fig. 6a) and $150 \mathrm{~s}$ (Fig. 6b)]. With the continuous heating [ $\mathrm{t}=1000 \mathrm{~s}$ (Fig. 6c) and $4000 \mathrm{~s}$ (Fig. 6d)], the isotherms deflects as the buoyancy effects increased for higher temperature deference and the liquid saturation decreased to a minimum value of, $s=0.02$. As the two-phase zone onset and spread at the upper wall [t=150 s (Fig. 8b) to $4000 \mathrm{~s}$ (Fig. 8d)], the buoyancy force increased and induced the fluid of higher temperature to flow in the upward direction towards the heated section. The generated vapor in the two-phase region flows primarily away from the heated suction, i.e. downwards flow direction in the TH case, but the incoming sub-cooled fluid with the buoyancy force derived the vapor to flow parallel to the upper wall. The non-thermal equilibrium condition between the fluid phase and the solid phase has a similar behavior to that of the $\mathrm{BH}$ case, where the higher solid phase temperature is seen above the heated suction and it reduced gradually far from the heated suction until it becomes almost identical to the fluid temperature at the channel exit to indicate the condition of thermal equilibrium as shown in Figs. $6 \mathrm{~d}$ and $7 \mathrm{~d}$.

At $\mathrm{t}=8000 \mathrm{~s}$ (Fig. 6e), the gravitational effect stretches the two-phase zone downwards to cover part of the channel exit at the steady state, $t=10000 \mathrm{~s}$ (Fig. 6f). During the entire simulation, the vapor velocity vectors are located close to the upper wall and gradually vanishing downwards to the condensation front and this can be attributed to the effect of the incoming sub-cooled liquid that caused a reduction in the vapor amount adjacent to the condensation front as shown in Fig. 8 f.

\subsection{Lower and upper wall discrete heat flux effects - bottom and top heated case (BTH)}

Figs. 9-11 show the influence of the lower and upper wall discrete heat flux $(\mathrm{qw}=100 \mathrm{~kW} / \mathrm{m} 2)$ on the transient behavior 
of fluid and solid phases. At the beginning of heating [ $\mathrm{t}=10 \mathrm{~s}$ (Fig. 9a) and $150 \mathrm{~s}$ (Fig. 9b)], a uniform dome shapes for the isotherms are proceed from the lower and upper wall towards the channel center. At $t=1000 \mathrm{~s}$ (Fig. 9c), the uniform dome shape is deformed with the boiling onset and vapor formation (Fig. 11c). The comparison of Figs. 9c and 10c reveals that the non-thermal equilibrium condition between the fluid phase and the solid phase is more obvious at $\mathrm{t}=1000 \mathrm{~s}$.

As the heating continuous [t=4000 s (Fig. 9d)], the spread two-phase zones from the lower and upper walls are met

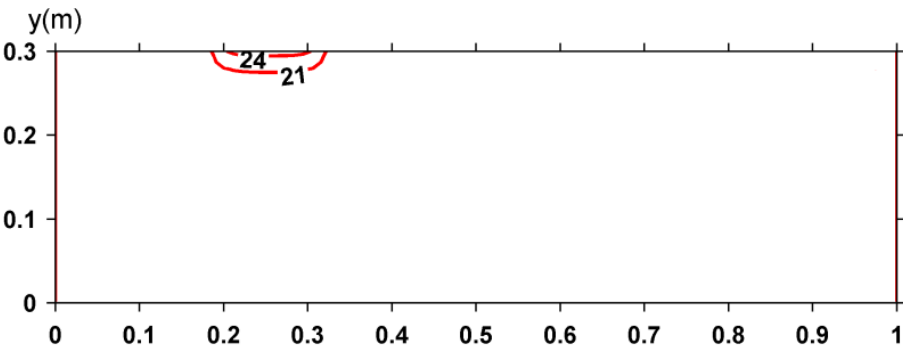

(a) $10 \mathrm{~s}$

$\mathrm{y}(\mathrm{m})$

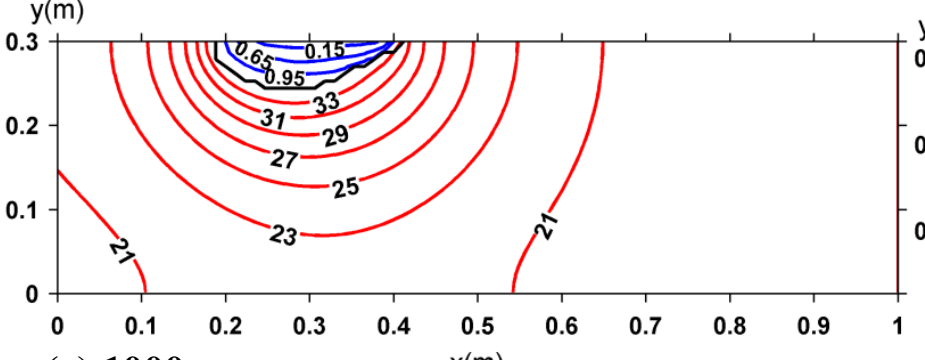

(c) $1000 \mathrm{~s}$

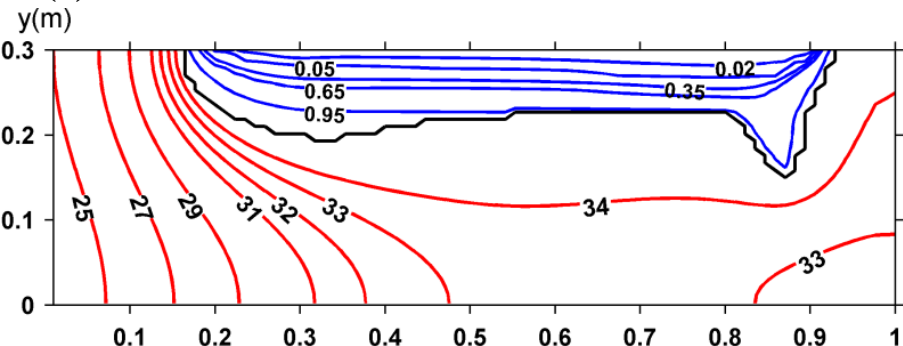

(e) $8000 \mathrm{~s}$ $\mathrm{x}(\mathrm{m})$ together at the channel center and the liquid saturation decreased towards the heated sections at the lower and upper walls with minimum values of, $s=0.3$ at the lower wall, and, $s=0.1$ at the upper wall. At the lower wall, the buoyancy force derived the fluid of higher temperature to flow upward and away from the heated section, while at the upper wall; the buoyancy force derived the fluid of higher temperature to flow upward towards the heated section. The flow direction of the hot fluid at the lower wall results in an increased in the heat transfer from the heated suction to the incoming subcooled $y(m)$

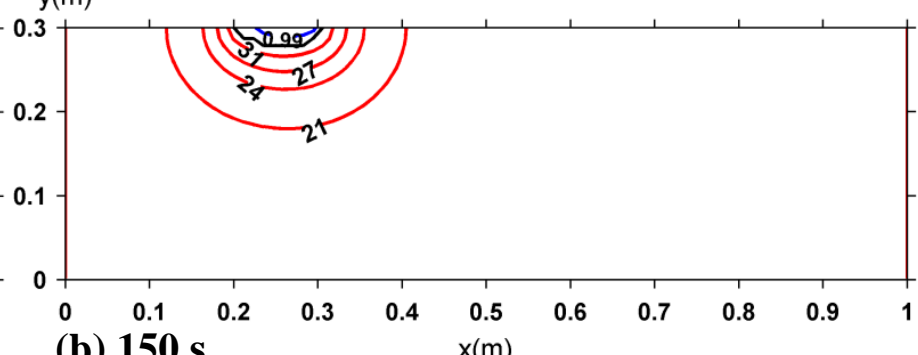

(b) $150 \mathrm{~s}$

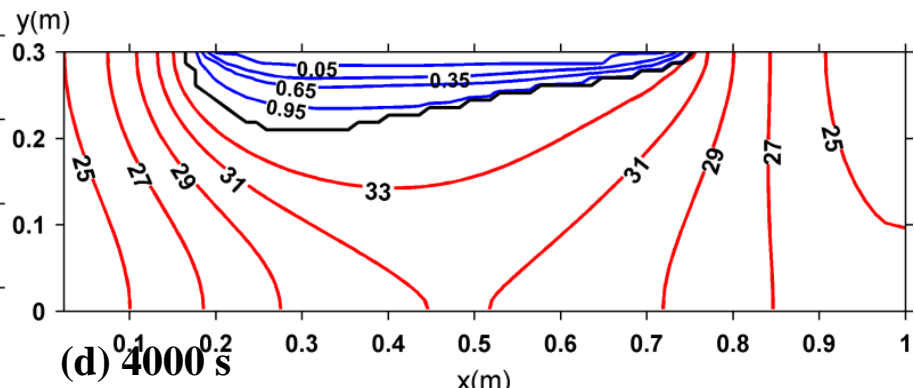

$y(m)$

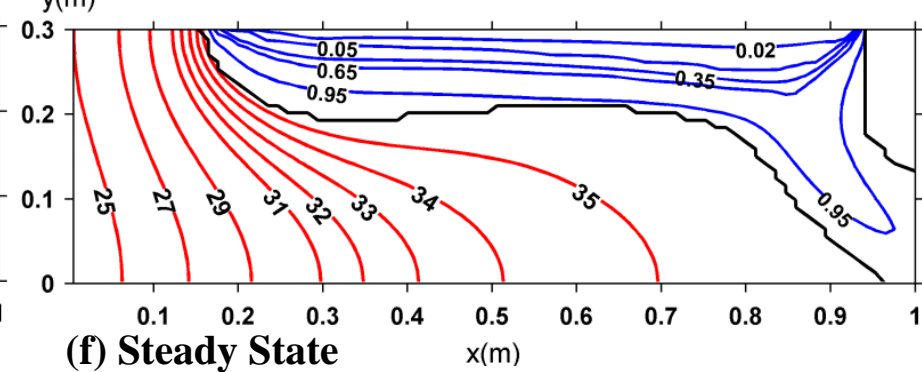

Fig. 6. Fluid temperature and liquid saturation contours (top heated TH).

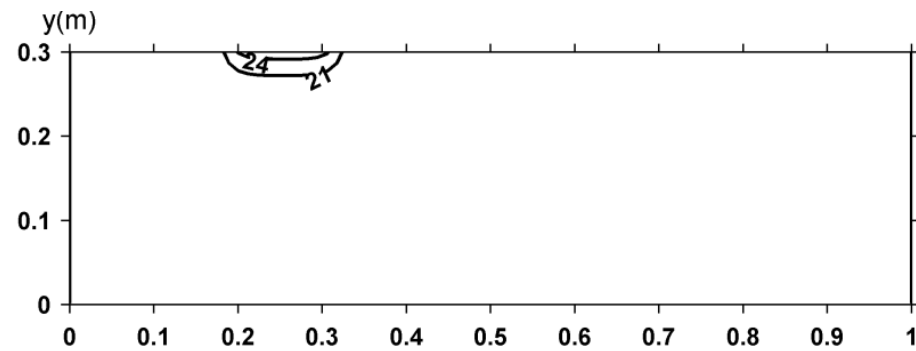

$\mathrm{y}(\mathrm{m})$

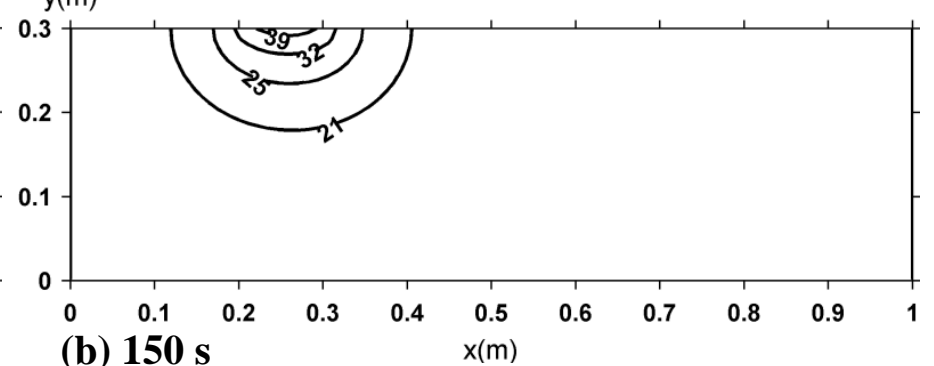

(a) $10 \mathrm{~s}$

$y(m)$

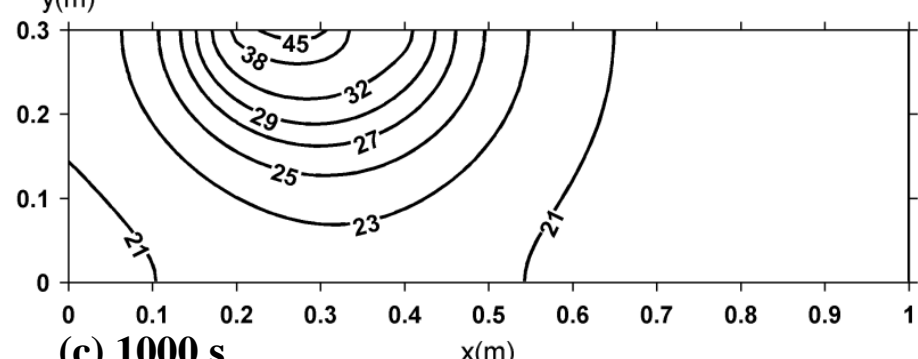

$\mathrm{y}(\mathrm{m})$

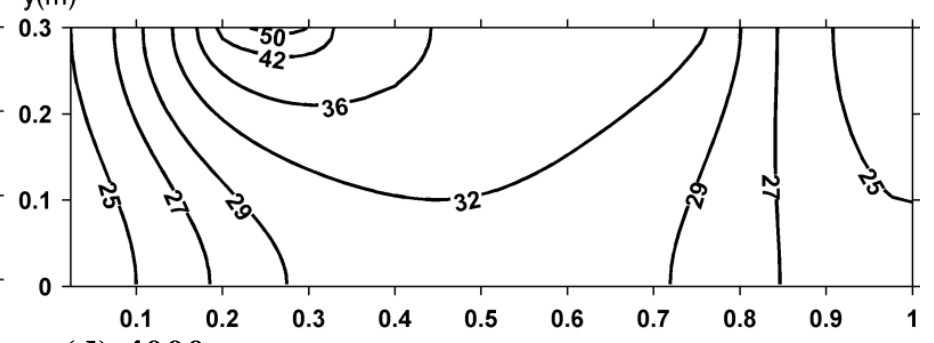

(d) $4000 \mathrm{~s}$ 

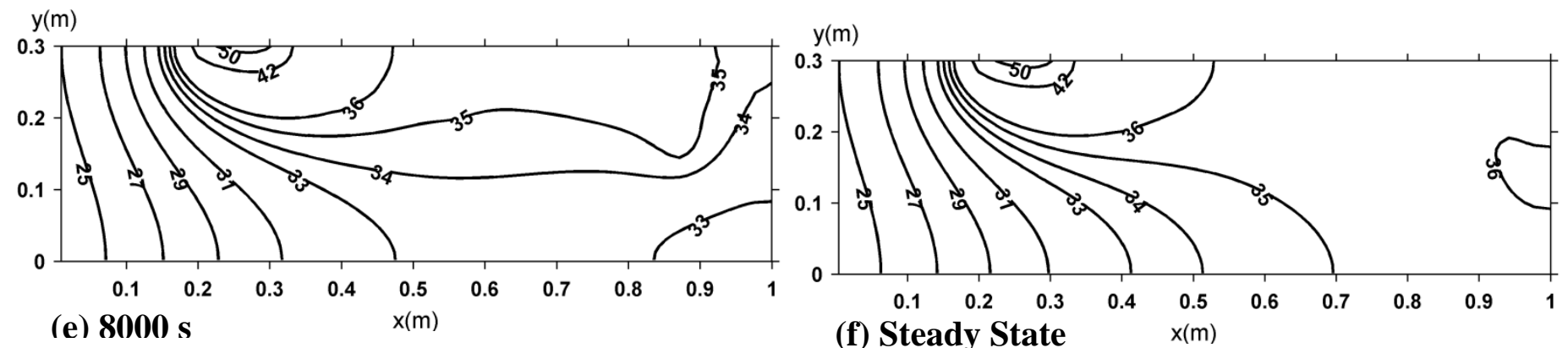

(e) $8000 \mathrm{~s}$

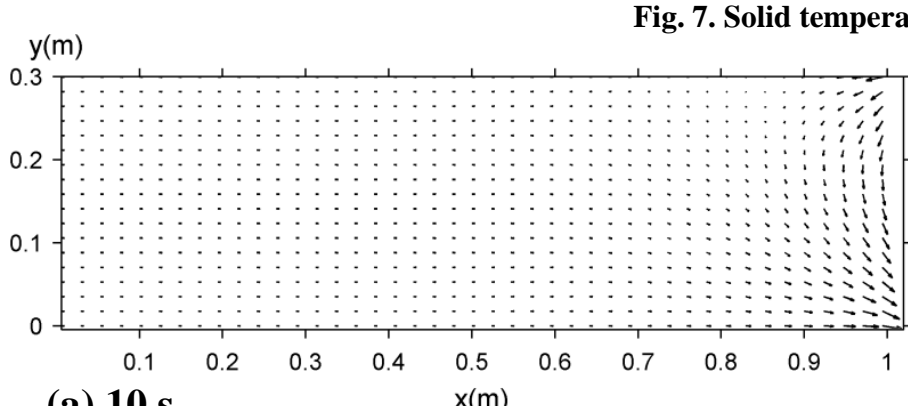

(a) $10 \mathrm{~s}$

$\mathrm{y}(\mathrm{m})$

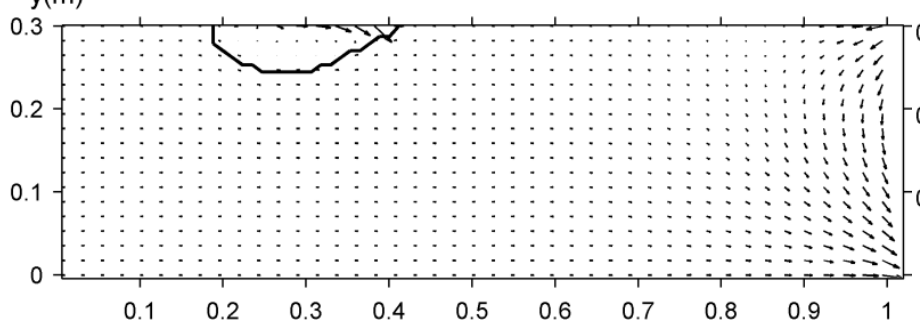

(c) $1000 \mathrm{~s}$

$\mathrm{y}(\mathrm{m})$

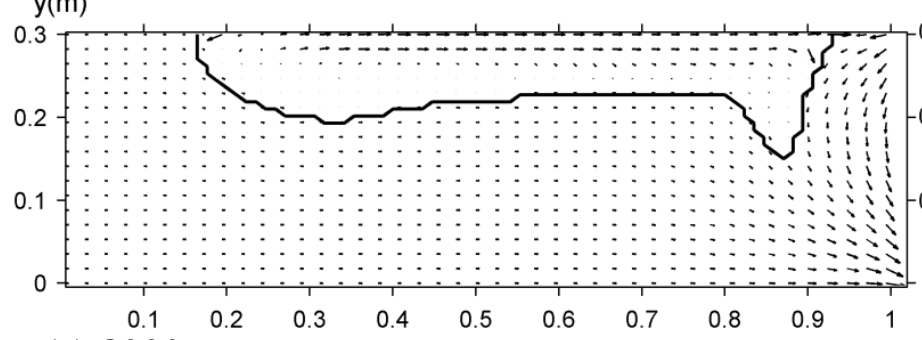

(e) $8000 \mathrm{~s}$

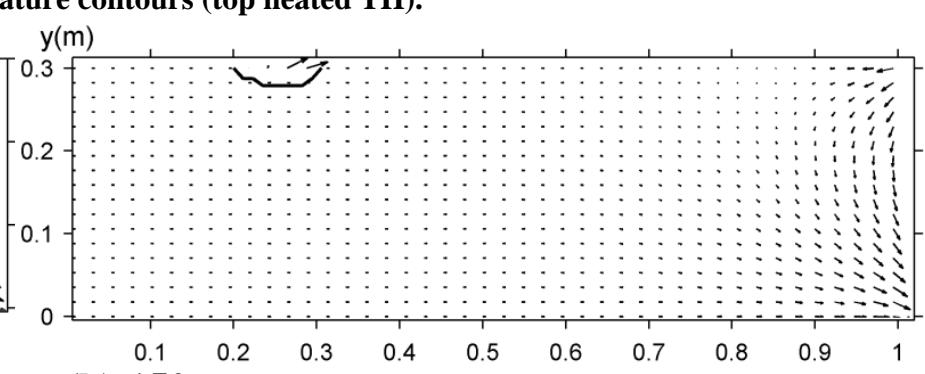

(b) $150 \mathrm{~s}$

$x(m)$

$y(m)$

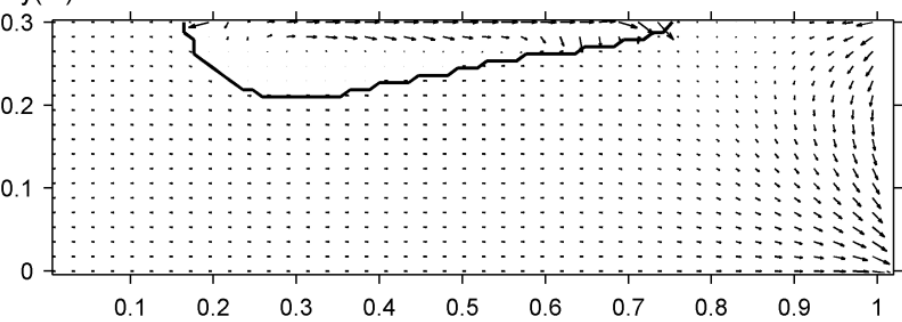

(d) $4000 \mathrm{~s}$

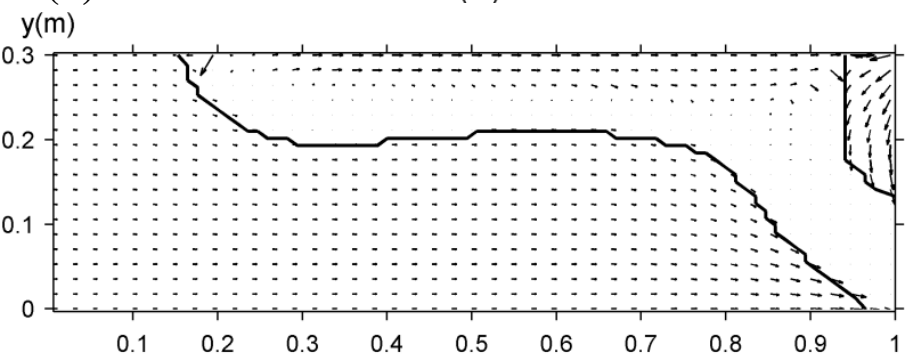

(f) Steady State

$x(m)$

Fig. 8. Liquid and vapor velocity vectors (top heated $\mathrm{TH}$ ).
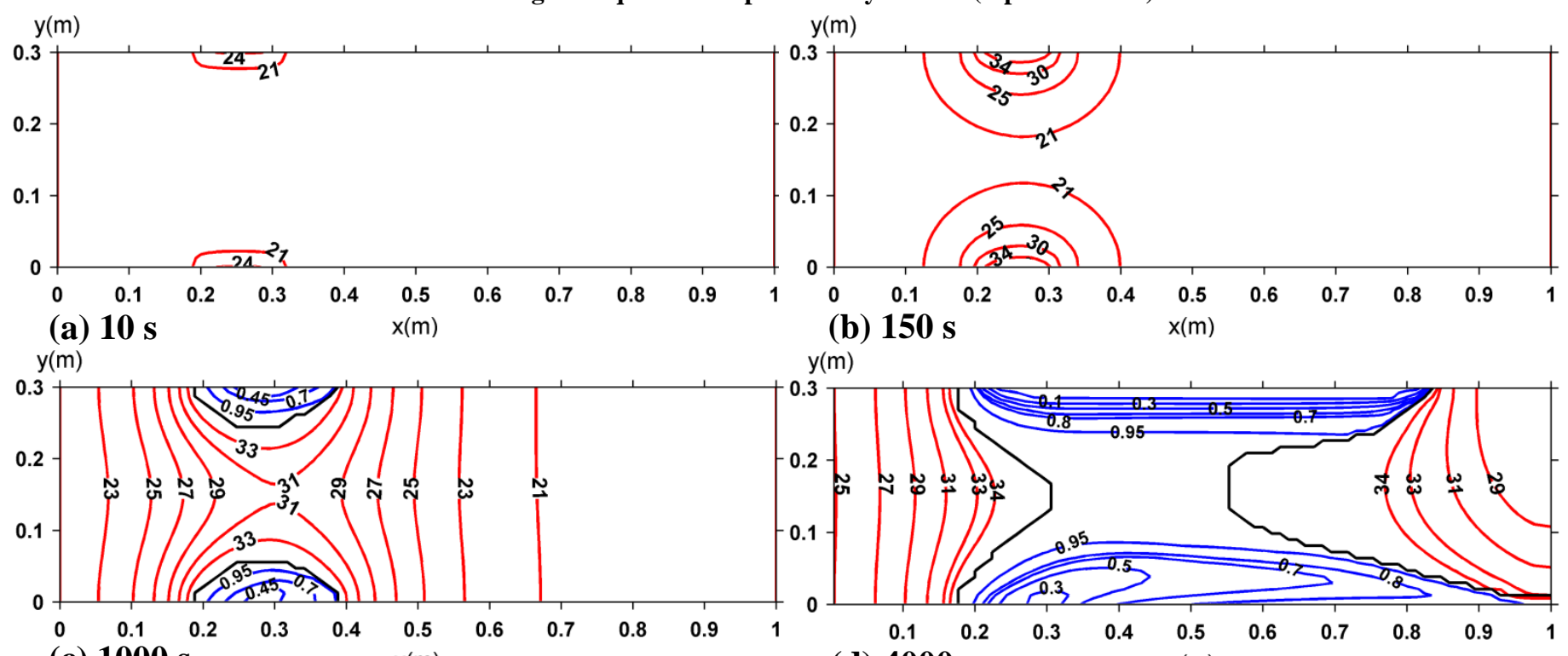

(b) $150 \mathrm{~s}$

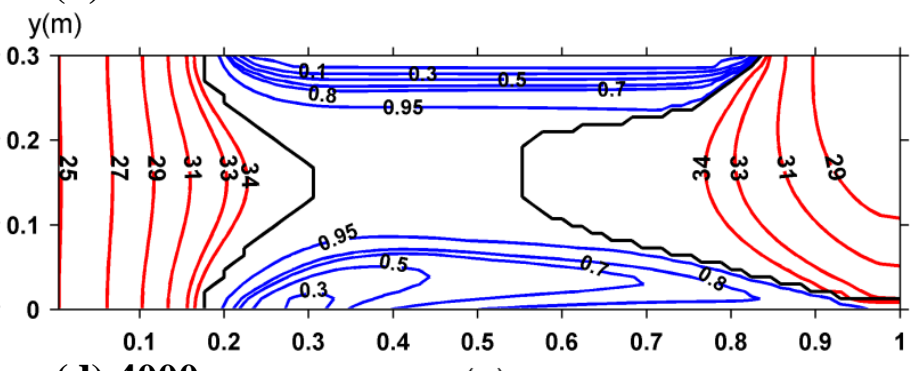

(c) $1000 \mathrm{~s}$

$\mathrm{x}(\mathrm{m})$

(d) $4000 \mathrm{~s}$ 

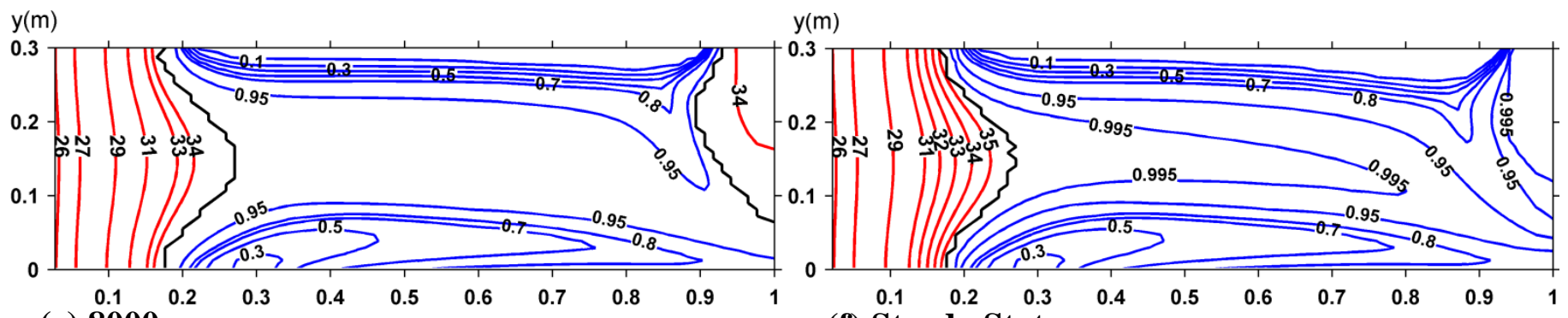

(e) $8000 \mathrm{~s}$

Fig. 9. Fluid temperature and liquid saturation contours (bottom and top heated BTH).
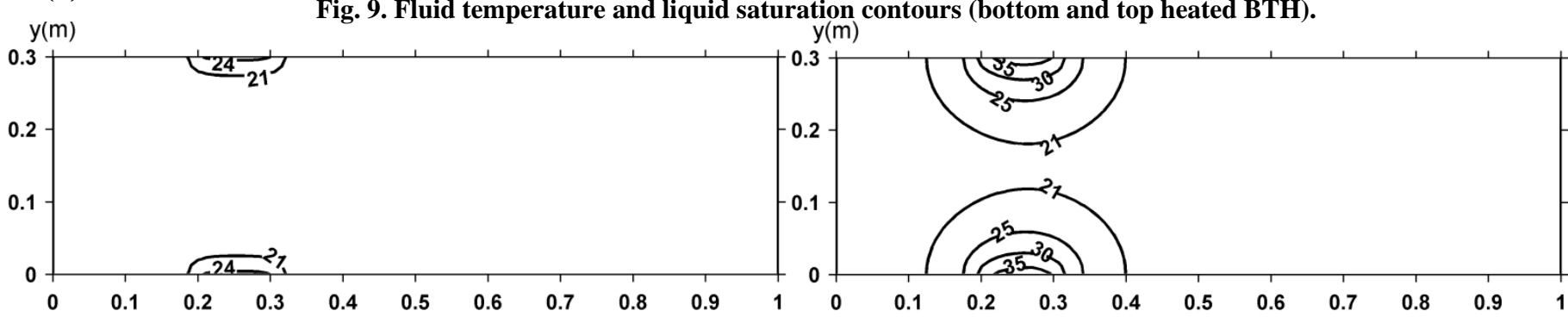

(a) $10 \mathrm{~s}$

$x(m)$

(b) $150 \mathrm{~s}$

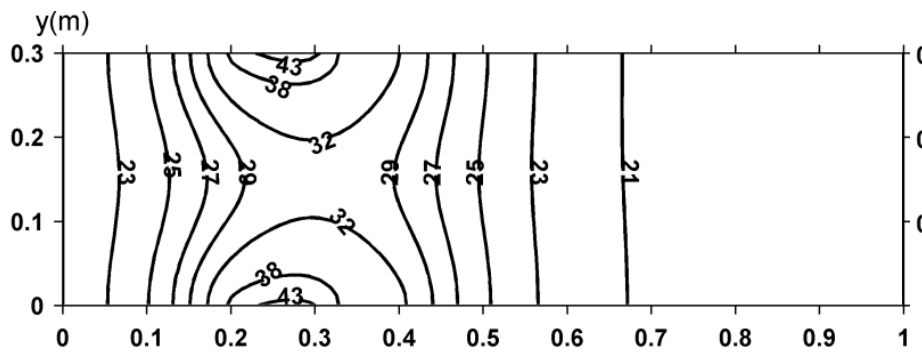

(c) $1000 \mathrm{~s}$

$x(m)$
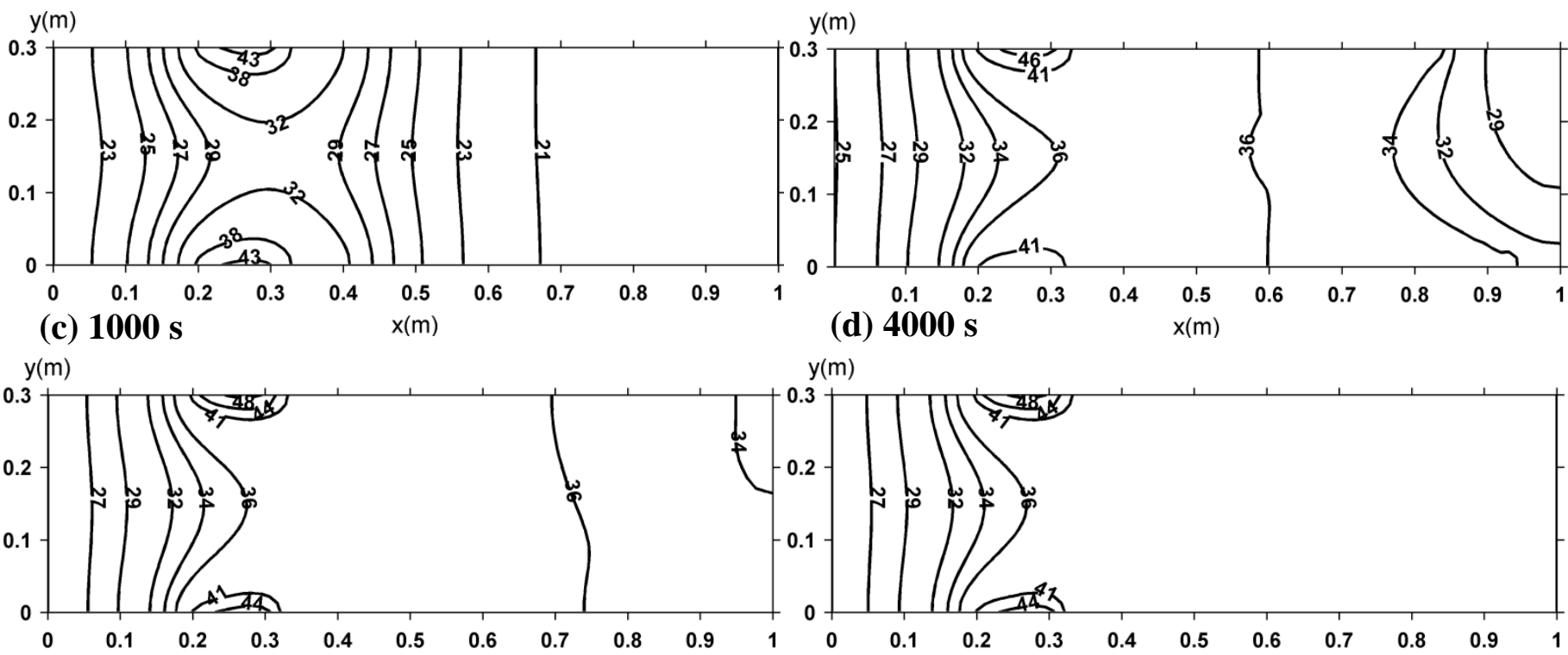

(d) $4000 \mathrm{~s}$

$x(m)$

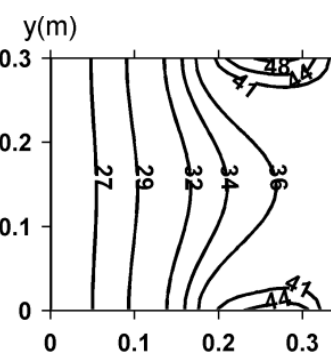

(e) $8000 \mathrm{~s}$

$x(m)$

(f) Steady State

Fig. 10. Solid temperature contours (bottom and top heated BTH).

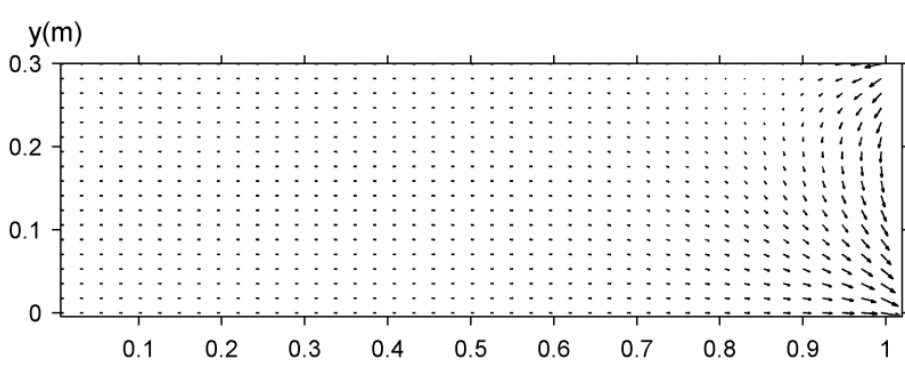

(a) $10 \mathrm{~s}$

$\mathrm{x}(\mathrm{m})$

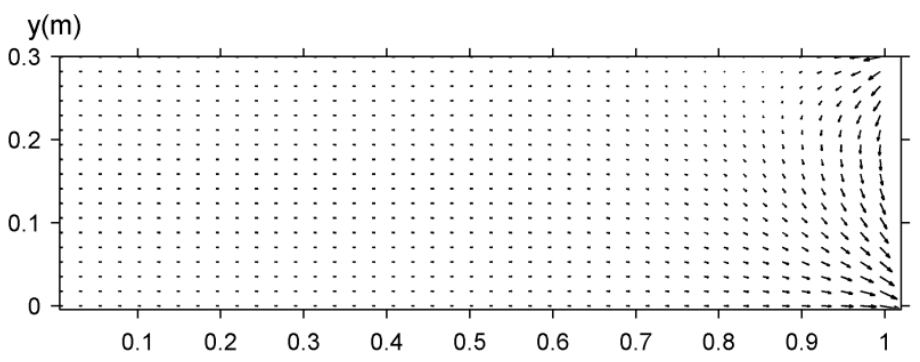

$\mathrm{y}(\mathrm{m})$

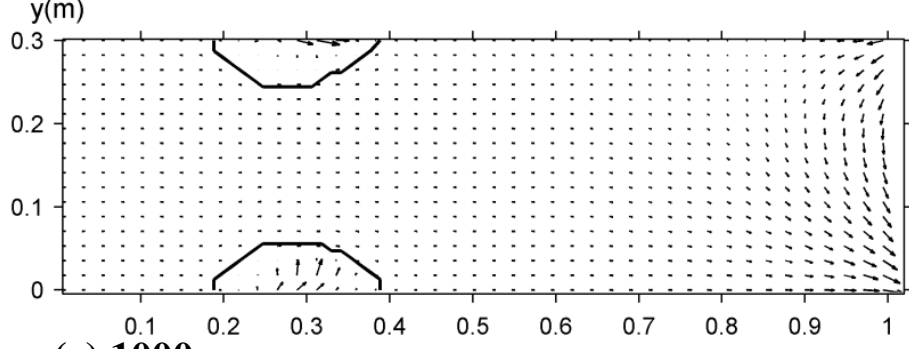

(b) $150 \mathrm{~s}$

$x(m)$

$\mathrm{y}(\mathrm{m})$

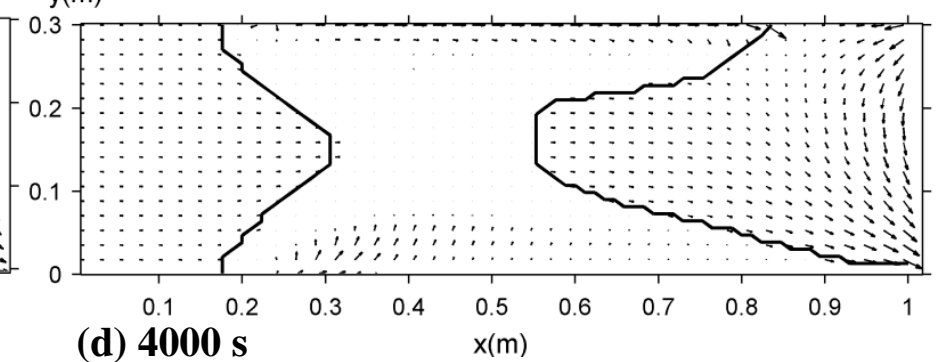




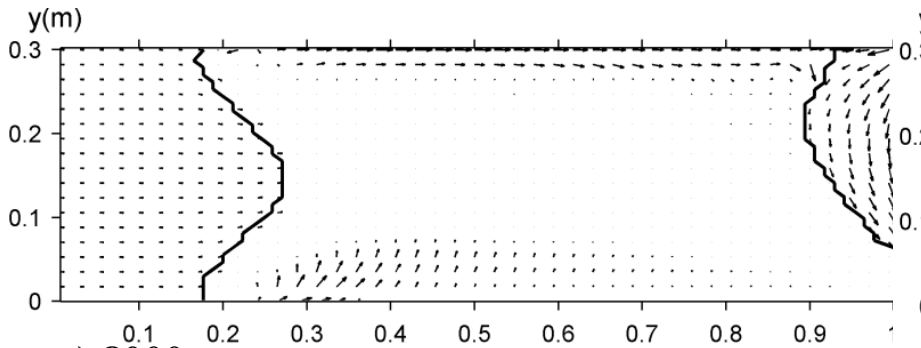

$\mathrm{y}(\mathrm{m})$

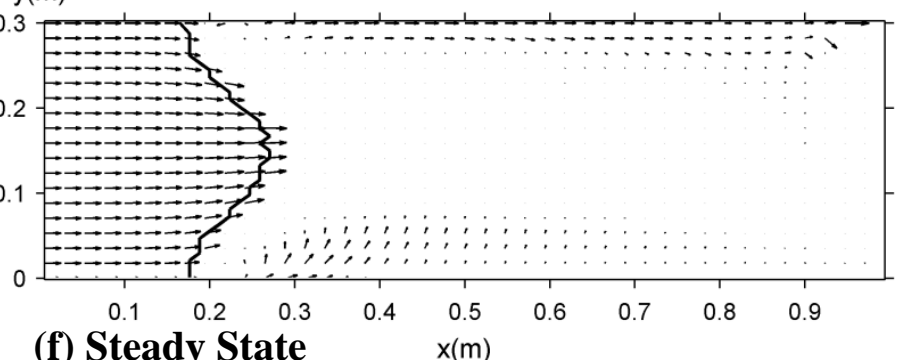

(e) $8000 \mathrm{~s}$

$x(m)$

(f) Steady State

Fig. 11. Liquid and vapor velocity vectors (bottom and top heated BTH).

fluid, on the contrary, the flow direction of the hot fluid at the upper wall results in a reduction in the heat transfer from the heated suction to the incoming sub-cooled fluid. The reduction in the heat transfer from the upper heated suction results in a lower liquid saturation value at the upper heated suction $(s=0.1)$ and higher liquid saturation value at the lower heated suction $(s=0.3)$ as shown in Fig. 9d. This finding lead to the following important result: the dryout zone in the case of BTH, if occurs, will be seen first at the upper wall. Fig. 10d is also show that because of the lower heat transfer from the upper heated suction, the non-thermal equilibrium condition is more obvious at the upper heated section (with $T_{s, \max }=46^{\circ} \mathrm{C}$ ) from that at the lower heated section (with $T_{s, \max }=41^{\circ} \mathrm{C}$ ).

As more time elapsed and reached the steady state, $[\mathrm{t}=10000$ s (Fig. 9f)], the two-phase zone expands to cover the entire porous channel downstream the heated sections at the upper and lower walls. At the channel exit, the gravity force stretch the liquid saturation contours at the upper wall downwards to meet those at the lower wall. The comparison between Figs. 9f and $10 \mathrm{f}$ show that the solid temperature distribution for the entire porous channel is almost identical to the fluid temperature distribution except above the heated sections where the non-thermal equilibrium condition is more obvious. This can be attributed to the lower heat flux that imposed in the case of BTH, namely, $\mathrm{q}_{\mathrm{w}}=100 \mathrm{~kW} / \mathrm{m}^{2}$. At the steady state, $t=10000 \mathrm{~s}$ (Fig. 11f), the vapor velocity vectors flow parallel to the upper wall and away from the lower wall with unclear vapor presence at the channel core due to the main stream effect.

\section{CONCLUSIONS}

A numerical solution is performed for transient boiling heat transfer through a horizontal channel that subjected to discrete heat flux and filled with high-conductivity material, copper, by using thermal non-equilibrium model TNE. The main conclusions of the present work are:

1) The minimum liquid saturation can be seen above the heated suction and increased gradually towards the condensation front.

2) The vapor velocity vectors flow parallel to the upper wall and away from the lower wall and the flow direction is extremely affected by the buoyancy force action at each wall.

3) In the two-phase region, the thermal non-equilibrium condition is remarkable as the solid phase temperatures increased beyond the saturation temperature.

4) The dryout zone will be seen first at the upper wall due to the lower heat transfer from the upper heated wall compared to that from the lower heated wall.

5) The non-thermal equilibrium condition is more obvious at the upper heated section from that at the lower heated section because of the lower heat transfer from the upper heated wall.

\section{REFERENCES}

[1] Wang, C. Y. and Cheng, P. 1997. Multiphase flow and heat transfer in porous media. Advances in Heat Transfer 30, 93-196.

[2] Wang, C.Y. and Beckermann, C. 1993. A two-phase mixture model of liquid-gas flow and heat transfer in capillary porous media-I Formulation. Int. J. Heat Mass Transfer 36 (11), 2747-2758.

[3] Bear, J. 1972. Dynamics of fluids in porous media. New York: Elsevier.

[4] Yuki, K., Abei, J., Hashizume, and Toda, H. S. January 2008. Numerical investigation of thermofluid flow characteristics with phase change against high heat flux in porous media. J. of Heat Transfer, Transactions of the ASME 130 (1), (12 pages).

[5] Peterson,G. P. and Chang, C. S. 1997. Heat transfer analysis and evaluation for two-phase flow in porouschannel heat sinks., Numerical Heat Transfer, Part A 31, 113-130.

[6] Peterson,G. P. and Chang, C. S. February 1998. Twophase heat dissipation utilizing porous-channels of highconductivity material. J. of Heat Transfer, Transactions of the ASME 120, 243-252.

[7] Baytas, A.C. and Pop, I. 2002. Free convection in a square porous cavity using a thermal non-equilibrium model. Int. J. Thermal Sci. 41, 861-870.

[8] Saeid, N.H. 2004. Analysis of mixed convection in a vertical porous layer using non-equilibrium model. Int. J. Heat Mass Transfer 47, 5619-5627.

[9] Saeid, N.H. and Mohamad A.A. 2005. Periodic free convection from a vertical plate in a saturated porous medium non-equilibrium model. Int. J. Heat Mass Transfer 48, 3855-3863.

[10] Badruddin, I.A., Zainal, Z.A. Narayana, P.A.A. and Seetharamu, K.N. 2006. Thermal non-equilibrium modeling of heat transfer through vertical annulus embedded with porous medium. Int. J. Heat Mass Transfer 49, 4955-4965.

[11] Ahmed, N.J.S., Badruddin, I.A., Kanesan, J., Zainal, Z.A. and Ahamed, K.S.N. 2011. Study of mixed convection in an annular vertical cylinder filled with saturated porous medium, using thermal non-equilibrium model. Int. J. Heat Mass Transfer 54, 3822-3825.

[12] Ergun, S. 1952. Fluid flow through packed columns, Chem. Eng. Prog. 48, 89-94.

[13] Dullien, F. A. L. 1979. Porous media fluid transport and 
pore structure. Acade Press, New York.

[14] Wakao, N. and Kaguei, S. 1982. Heat and mass transfer in packed beds. Gordon and Breach, New York.

[15] Rohsenow, W. M. 1952. A method of correlating heat transfer data for surface boiling of liquids. Trans. ASME 74, 969-976.

[16] Beaton, C.F. and Hewitt, G. F. 1989. Physical Property Date for the Design Engineer. Hemisphere Publishing Corporation, New York.

[17] Oda, Y., Iwai, H., Suzuki, K. and Yoshida, H. 2003. Numerical study of conjugate heat transfer for channel filled with porous insert. The Sixth ASME-JSME Thermal Engineering Joint Conference, Paper No. TEDAJ03-418.

[18] Patankar, S. V. 1980. Numerical heat transfer and fluid flow. New York: Hemisphere.

\section{APPENDIX}

\section{Nomenclature}

a specific surface area

c specific heat

$C_{E} \quad$ ergun constant

$C_{s f}$ surface/liquid parameter of the Rohsenow correlation

$d_{p}$ particle diameter

$D(s)$ capillary diffusion coefficient

$f_{s} \quad$ hindrance function

g gravitational acceleration

$G^{\prime \prime} \quad$ mass flow rate ratio

$h$ enthalpy

$h_{f g}$ latent heat of vaporization

$h_{L} \quad$ local heat transfer coefficient at the heated wall

$h_{m}$ mean heat transfer coefficient

$h_{s f}$ heat transfer coefficient between solid-phase and fluidphase

$H \quad$ volumetric enthalpy

$k$ thermal conductivity

$k_{r} \quad$ relative permeability

$K \quad$ absolute permeability

$L \quad$ length of the square porous channel

$M \quad$ inertia permeability $p \quad$ pressure

Pr Prandtl number

$q \quad$ heat flux

$Q_{s f} \quad$ volumetric heat transfer rate between solid-phase and fluid-phase

$\operatorname{Re}_{p} \quad$ Reynolds number based on particle diameter

$s \quad$ liquid saturation

$t$ time

$T$ temperature

$\mathrm{u} \quad$ superficial velocity component in $\mathrm{x}$-direction

$\mathrm{v}$ superficial velocity component in y-direction

u superficial velocity vector

$\mathrm{x}, \mathrm{y} \quad$ space coordinates

\section{Greek Symbols}

$\beta \quad$ Forchheimer coefficient

$\gamma_{h}$ two-phase advection correction coefficient

$\Gamma_{h} \quad$ effective thermal diffusion coefficient

$\Delta \rho \quad$ density difference $=\left(\rho_{l}-\rho_{v}\right)$

$\varepsilon \quad$ porosity

$\lambda$ relative mobility

$\mu \quad$ dynamic viscosity

$v \quad$ kinetic viscosity

$\phi \quad$ angle of inclination

$\rho$ density

$\sigma \quad$ surface tension

$\Omega \quad$ effective heat capacitance ratio

\begin{tabular}{ll}
\multicolumn{2}{l}{ Subscripts } \\
$b$ & bulk \\
$c$ & capillary \\
eff & effective \\
$f$ & fluid phase \\
$l$ & liquid phase \\
in & inlet \\
$k$ & kinetic property \\
m & mean \\
$s$ & solid phase \\
sat & saturated state \\
$v$ & vapor phase \\
w & wall
\end{tabular}

